\section{Halogen-abstraction reactions from chloromethane and bromomethane molecules by alkaline-earth monocations}

\author{
Pilar Redondo, ${ }^{a}$ Antonio Largo, ${ }^{a}$ Víctor Manuel Rayón, ${ }^{a}$ Germán Molpeceres, ${ }^{a}$ \\ José Ángel Sordo ${ }^{\mathrm{b}}$ and Carmen Barrientos ${ }^{* a}$
}

The reactions, in the gas phase, between alkali-earth monocations $\left(\mathrm{Mg}^{+}, \mathrm{Ca}^{+}, \mathrm{Sr}^{+}, \mathrm{Ba}^{+}\right)$and $\mathrm{CH}_{3} \mathrm{X}$ $(\mathrm{X}=\mathrm{Cl}, \mathrm{Br}$ ) have been theoretically studied. The stationary points on the potential energy surfaces were characterized at the Density Functional Theory level on the framework of the mPW1K functional with the QZVPP Ahlrichs's basis sets. A complementary kinetics study has also been performed using conventional/variational microcanonical transition state theory. In the reactions of $\mathrm{Mg}^{+}$with either chloro- or bromomethane the transition structure lies in energy clearly above the reactants rendering thermal activation of $\mathrm{CH}_{3} \mathrm{Cl}$ or $\mathrm{CH}_{3} \mathrm{Br}$ extremely improbable. The remaining reactions are exothermic and barrierless processes; thus carbon-halogen bonds in chloro- or bromomethane can be activated by calcium, strontium or barium monocations to obtain the metal halogen cation and the methyl radical. The Mulliken population analysis for the stationary points of the potential energy surfaces supports a "harpoon"-like mechanism for the halogen-atom abstraction processes. An analysis of the bonding situation for the stationary points on the potential energy surface has also been performed in the framework of the quantum theory of atoms in molecules. www.rsc.org/pccp

Received 14th May 2014, Accepted 16th June 2014

DOI: $10.1039 / c 4 c p 02094 d$

\section{Introduction}

The study of reactions in the gas-phase provides the opportunity to research the intrinsic reaction mechanism avoiding disturbing effects arising from the presence of the solvent. In particular, the study of the interaction between metal cations and alkyl halides has attracted attention in the last two decades. In addition to their importance in different areas of chemistry such as organometallic chemistry, ${ }^{1}$ biochemistry, ${ }^{2}$ and atmospheric chemistry, ${ }^{3}$ these gas-phase reactions allow us to analyze the possible selective metal-mediated activation of carbon-hydrogen and carbonhalide bonds.

In the last few years, numerous experimental studies have been reported including gas-phase reactions of metal cations with halogenated methanes. The development of ion sources and modern mass spectrometric techniques has led to a variety of thermodynamic, kinetic, and mechanistic information about gas-phase ion-molecule reactions. Mass spectrometers have proven to be powerful tools for studying the kinetics, mechanisms, and product distributions of gas phase bimolecular reactions.

${ }^{a}$ Departamento de Química Física y Química Inorgánica, Facultad de Ciencias, Universidad de Valladolid, 47011 Valladolid, Spain

55 Laboratorio de Quimica Computacional, Departamento de Quimica Física y Analitica, Facultad de Química, Universidad de Oviedo, 33006 Oviedo, Spain
To study ion-molecule reactions, under highly controlled conditions, different mass-spectrometric techniques, such as selected-ion flow tubes (SIFT), ${ }^{4,5}$ guided ion beam (GIB), ${ }^{6}$ and ion cyclotron resonance (ICR) ${ }^{7}$ have been developed.

Alkyl halides are interesting substrates for reactions with metal cations, as they provide an opportunity for competition between $\mathrm{C}-\mathrm{H}$ and $\mathrm{C}-\mathrm{X}$ bond activation. In particular, methyl halides, $\mathrm{CH}_{3} \mathrm{X}(\mathrm{X}=\mathrm{F}, \mathrm{Cl}, \mathrm{Br})$, have substantial dipole moments $\left(\mu=1.8471 \mathrm{D}^{8}\left(\mathrm{CH}_{3} \mathrm{~F}\right), 1.88 \mathrm{D}^{9}\left(\mathrm{CH}_{3} \mathrm{Cl}\right)\right.$ and $\left.1.81 \mathrm{D}^{9}\left(\mathrm{CH}_{3} \mathrm{Br}\right)\right)$ so are amenable to electrostatic deceleration and trapping and the different polarities of the $\mathrm{C}-\mathrm{X}$ bond might contribute to interesting reactive features. In fact, the strength of the $\mathrm{C}-\mathrm{X}$ bonds in halogenated compounds is directly related to their dissociation ability and the energetically accessible pathways available for their primary processes. Besides this intrinsic interest, chloromethane and bromomethane have an unquestionable relevance in atmospheric chemistry because they are involved in various catalytic atmospheric reaction cycles responsible for the depletion of the ozone layer.

The reactions between methyl fluoride and different monocations have been studied extensively in the past few years (see below), mainly because they provide insight into carbon-fluorine bond activation. Another interesting topic regarding reactions between monocations and halocarbons concerns the mechanism through which these reactions proceed. Basically, two different 
1 mechanisms have been proposed: (a) single-electron transfer (SET), namely, "harpoon"-like mechanism and (b) insertion-elimination mechanism. ${ }^{10,11}$ The main evidence supporting the "harpoon"-like mechanism is, in principle, the inverse correlation between the second ionization energy (SIE) of the metal and the efficiency of the reaction.

In an exhaustive study reported in 2006, Zhao et al. ${ }^{1}$ carried out a systematic analysis of the gas-phase reactions of $\mathrm{CH}_{3} \mathrm{~F}$ with 46 different atomic cations, including 29 transition-metal

10 cations and 17 main-group cations, using an inductively coupled plasma/selected-ion flow tube tandem mass spectrometer (ICP/SIFT). In these reactions, different channels were observed depending essentially on the atomic monocation considered.

15 Some years ago, Harvey et al. ${ }^{12}$ carried out both experimental and theoretical studies on the mechanism of the reaction of $\mathrm{Ca}^{+}$ with fluoromethane. From those studies the authors pointed out that a "harpoon"-like mechanism seems to operate in this reaction. However a correlation between SIEs and reactivity was not found. The authors concluded that the mechanism through which metal-mediated activation of carbon-halogen bonding takes place is not fully understood.

In order to confirm Harvey et al.'s ${ }^{12}$ assertions, we performed a theoretical study of the reaction between methyl fluoride and the calcium monocation. ${ }^{13}$ One of the main conclusions of our study was to emphasize the importance of the "outer" and "inner" transition states located on the Potential Energy Surface (PES) to control the kinetics of the process. Thus, the correlation, or lack of correlation, between reaction rate constants and SIEs of the metal might be rationalized in terms of a two transition state model.

This initial research was later complemented by including other alkaline-earth monocations ${ }^{14}$ in our study. Calculations suggested that these reactions seem to proceed through a "harpoon"-like mechanism, but further work, including other metal cations, was necessary to support the validity of the mechanistic findings reported. Recently, and, in order to get insight into the selectivity and mechanism of carbon-fluorine bond activation of fluoromethane, we have extended our 40 research to different first-row transition metal monocations $\left(\mathrm{Sc}^{+}, \mathrm{Ti}^{+}, \mathrm{V}^{+}, \mathrm{Zn}^{+}\right),{ }^{15}$ and main fourth-period monocations $\left(\mathrm{Ga}^{+}\right.$, $\left.\mathrm{Ge}^{+}, \mathrm{As}^{+}, \mathrm{Se}^{+}\right) .{ }^{16}$ In the case of first-row transition metal monocations we found theoretical evidence for a "harpoon"-like mechanism for the fluorine-atom abstraction process that ate via electron transfer from the transition metal cation to the $\mathrm{CH}_{3} \mathrm{~F}$ substrate in the transition structure. However, we did not find the expected relationship between the SIEs of the metal and the efficiency of the reaction. We just found such a correlation for the "inner" rate constant. Finally, regarding the study on main-fourthperiod monocations, we suggest that besides a "harpoon"-like mechanism, the possibility of an insertion-elimination process seems to play an important role in the cases where an oxidative addition was electronically plausible.

Although reactions between methyl fluoride and different monocations have been studied extensively, reactions including chloro- and bromomethane have received relatively little attention.
Following this line of inquiry and in order to complete our previous studies, in this paper we present a theoretical analysis of the effect of the halide on reactivity of alkali-earth metal monocations with monosubstituted halogenated methanes:

$\mathrm{M}^{+}(\mathrm{Mg}, \mathrm{Ca}, \mathrm{Sr}, \mathrm{Ba})+\mathrm{CH}_{3} \mathrm{X}(\mathrm{X}=\mathrm{Cl}, \mathrm{Br}) \rightarrow$

Thermodynamical, kinetic and mechanistic implications of the results will be examined. In addition, we will characterize the molecular mechanism of these reactions from the redistribution of the electron density along the stationary points in the framework of the Mulliken population analysis (MPA) and make use of Bader's Quantum theory of Atoms in Molecules (QTAIM). ${ }^{17}$

It is important to stress that the results reported in this work do provide a full mechanistic prediction about the studied processes in the sense that we fill the gap between quantum calculations and kinetics prediction (directly comparable with experimental data) by employing an appropriate theoretical kinetics model. In other words, the predicted rate constants should be, according to our previous work, ${ }^{13-16}$ in reasonable good agreement with the corresponding experimental values when available.

\section{Computational methods}

As in our previous kinetics studies, ${ }^{13-16}$ we have explored the PESs for the reactions between $\mathrm{M}^{+}(\mathrm{Mg}, \mathrm{Ca}, \mathrm{Sr}, \mathrm{Ba})$ and $\mathrm{CH}_{3} \mathrm{X}$ $(\mathrm{X}=\mathrm{Cl}, \mathrm{Br})$ at the Density Functional Theory (DFT) level. In particular, we have chosen the second-generation modifiedWang-1-parameter method for the kinetics (mPW1K) functional, ${ }^{18}$ which has previously proved its ability to describe the PESs of reactions between analogous systems and gives accurate barrier heights. ${ }^{19}$ This functional is based on a modified version of the Perdew-Wang gradient-corrected exchange functional by Adamo and Barone ${ }^{20}$ and the Perdew-Wang gradient-corrected correlation functional. Regarding basis sets, we have employed Ahlrichs' quadruple- $\zeta$ quality (QZVPP) basis sets. ${ }^{21}$ For $\mathrm{Sr}$ and $\mathrm{Ba}$, inner shell electrons are modeled by effective core potentials (ECPs) that reduce the number of basis functions and, more importantly, account for the scalar relativistic effects. ${ }^{21}$

Geometric parameters have been computed using tight convergence criteria and an ultrafine grid for numerical calculations. For each stationary point, we have calculated vibrational frequencies and zero-point energy (ZPE) corrections within the harmonic approximation at the mPW1K/QZVPP level of theory. The nature of the stationary points on the PESs has been determined by the number of negative eigenvalues of the analytical Hessian (zero in local minima and one in first-order saddle points). To explore the connections between transitionstate structures and adjacent minima the intrinsic reaction coordinate (IRC) ${ }^{22}$ has been used.

ZPEs and thermodynamic functions were determined by using the statistical thermodynamic formulation of partition functions within the ideal gas, rigid rotor and harmonic oscillator models. A temperature of $298.15 \mathrm{~K}$ and a pressure 
of $1 \mathrm{~atm}$ have been assumed. Quantum and thermodynamics calculations were carried out using the GAUSSIAN 09 package of programs. ${ }^{23}$

The molecular mechanism of the reactions studied in the present work was characterized from the redistribution of the electronic charge density, $\rho(r)$, along the reaction path connecting the stationary points, in the framework of Bader's Quantum Theory of Atoms in Molecules (QTAIM). ${ }^{17}$ This model based on quantum mechanics and physical observables also allows a rigorous characterization of the nature of the bonding in different species involved in the PESs of these reactions.

In the context of the QTAIM model two limiting types of interactions can be identified: shared interactions and closedshell interactions. ${ }^{24}$ In a shared interaction, typical of covalent compounds, the nuclei are bound as a consequence of lowering of the potential energy associated with the concentration of the electronic charge shared between the nuclei; this is reflected in relatively large values of $\rho(r)$ at the critical point and negative values of the Laplacian, $\nabla^{2} \rho(r)$. The second limiting type of atomic interaction is that occurring between closed-shell systems, such as those found in ionic bonds or van der Waals molecules, for instance. In these interactions, $\rho(r)$ value is relatively low and the value of $\nabla^{2} \rho(r)$ is positive. Nevertheless, between these limiting types there is a whole spectrum of intermediate interactions. It should be noted that for elements with more than half-filled valence shells, a lack of the expected density accumulations along the bonds can be found. ${ }^{25,26}$ Typical examples are the $\mathrm{F}-\mathrm{F}$ bond in the $\mathrm{F}_{2}$ molecule and the $\mathrm{O}-\mathrm{O}$ bond in $\mathrm{H}_{2} \mathrm{O}_{2}$.

The total energy density $H(r)$ is another useful property to characterize the degree of covalence of a bond. It is defined as the sum of the potential energy density $V(r)$ and the gradient kinetic energy density $G(r)$ at a critical point. If $H(r)$ value is negative, the system is stabilized by the accumulation of electronic charge in the internuclear region, which is a typical characteristic of a covalent interaction. ${ }^{27}$ When the value of $H(r)$ is positive, depletion of electronic density from the internuclear region takes place, a characteristic of ionic interactions and van der Waals systems. ${ }^{27}$ We can also quantitatively analyze the covalent character of an interaction by taking into account the $|V(r)| / G(r)$ ratio. The value of this ratio is greater than 2 in covalent interactions, lower than 1 for non-covalent interactions and between 1 and 2 for partially covalent bonds.

Total electron densities were obtained at the mPW1K/QZVPP level. In all calculations, we assessed the accuracy of the integration over the atomic basin $(\Omega)$ by the magnitude of the corresponding Lagrangian function, $L(\Omega),(-(1 / 4)$ times the atomic integral of the Laplacian of electron density), which, in all cases, was lower than $10^{-4}$ a.u. The topological analysis of electronic charge density was performed for each stationary point on the PESs using Keith's AIMAll package ${ }^{28}$ including standard thresholds.

Bearing in mind the experimental data available on the $\mathrm{CH}_{3} \mathrm{~F}$ reactions, we have focused on the $\mathrm{M}^{+}+\mathrm{CH}_{3} \mathrm{X}$ primary products. Other channels involving the formation of $\mathrm{HX}, \mathrm{H}_{2}$ or MH products have not been considered in the present work.

The PESs for the reactions considered in this study could be represented by a three step scheme. The first step corresponds to a barrierless interaction between the metal monocation $\left(\mathrm{M}^{+}\right)$and the halogen atom of the halomethane molecule $\left(\mathrm{CH}_{3} \mathrm{X}\right)$ giving a stable intermediate $\mathrm{C}_{1}$. In the second stage, the intermediate $\mathrm{C}_{1}$ converts to the insertion complex $\mathrm{C}_{2}$ via a first order saddle point transition structure, TS2. Finally, from the intermediate $\mathrm{C}_{2}$, the formation of products (methyl radical and $\mathrm{MX}^{+}$) takes place through a barrierless process. A simplified scheme of the energy profile for the $\mathrm{M}^{+}+\mathrm{CH}_{3} \mathrm{X}$ reactions is shown in Fig. 1 .

For kinetics determinations, we have used a model proposed by Mozurkewich and Benson, ${ }^{29}$ and based on the Rice-RamspergerKassel-Marcus (RRKM) theory, for calculating rate constants of bimolecular reactions with negative activation energies and curved Arrhenius plots. These reactions can be mechanistically explained by assuming that an intermediate complex is formed and the ratedetermining step involves a tight transition state with a rather small or negative potential energy relative to the reactants. The main assumption in the Mozurkewich and Benson model ${ }^{29}$ is that the pressure is low enough so that the intermediates do not undergo any subsequent collision (collisionless regime with the total energy $E$ and total angular momentum $J$ conserved).

The general scheme for the reactions studied in the present work can be depicted by

$$
\mathrm{R} \underset{k_{-1}}{\stackrel{k_{1}}{\rightleftharpoons}} \mathrm{C}_{1}^{*} \stackrel{k_{2}}{\underset{k_{-2}}{\rightleftharpoons}} \mathrm{C}_{2}^{*} \stackrel{k_{3}}{\longrightarrow} \mathrm{P}
$$

Fig. 1 General representation of the energetic profile of the $\mathrm{M}^{+}+\mathrm{CH}_{3} \mathrm{X}$ reactions $(\mathrm{M}=\mathrm{Mg}, \mathrm{Ca}, \mathrm{Sr}, \mathrm{Ba} ; \mathrm{X}=\mathrm{Cl}, \mathrm{Br}$ ). 
1 where $\mathrm{R}$ and $\mathrm{P}$ stand for reactants and products, respectively, and $\mathrm{C}_{1}{ }^{*}, \mathrm{C}_{2}{ }^{*}$ represent "hot" intermediates.

All the molecular systems included in the PESs were treated as prolate symmetry top rotors since they exhibit rotational constants fulfilling $A_{i}>B_{i} \approx C_{i}$. The rotational energy levels were computed in terms of the quantum numbers $J$ and $K$ :

$$
E_{i}(J, K)=J(J+1) B_{i}+\left(A_{i}-B_{i}\right) K^{2}
$$

The quantum number $J$ is conserved during the reaction; nevertheless, the $K$-rotor is treated as active ${ }^{30-32}$ when computing the sum of states $\left(W_{i}(E, J)\right.$ functions).

Following Tschuikow-Roux and co-workers, ${ }^{33}$ the equilibrium concentrations of the intermediates, $\left[C_{i}(E, J)\right] \mathrm{eq}$, are related to total equilibrium concentrations, $\left[C_{i}\right] \mathrm{eq}$, by

$$
\left[C_{i}(E, J)\right]_{\mathrm{eq}}=\frac{N_{C_{i}}(E, J) \cdot\left[C_{i}\right]_{\mathrm{eq}}}{Q_{C_{i}}} \exp \left[-\left(E-V_{C_{i}}\right) / R T\right]
$$

where $Q_{C_{i}}$ is the partition function of intermediate $C_{i}$ with the center of mass motion factored out and $V_{C_{i}}$ is the lowest energy of $C_{i}$. The steady-state concentration is related to it by means of ${ }^{29}$

$$
\left[C_{i}(E, J)\right]=\frac{\left[C_{i}(E, J)\right]_{\mathrm{eq}}}{1+\frac{W_{i+1}(E, J)}{W_{i}(E, J)}}
$$

where $g_{J K}$ is the degeneracy associated with the $J K$ rotational

The sums of states, $W_{i}(E, J)$, were computed by means of the Forst algorithm ${ }^{30}$ using the appropriate frequencies and inertia moments for the transition states.

We have applied the $E, J$-resolved microcanonical variational transition state theory ( $\mu \mathrm{VTST}$ ) in its vibrator formulation ${ }^{34,35}$ for the process of formation of the initial intermediate, $\mathrm{C}_{1}$, and the exit channel, where no transition structures (TS1 and TS3 respectively) were located. In these regions, we have constructed distinguished-reaction coordinate paths (DCPs). ${ }^{36,37}$ The points on the DCP were obtained by fixing one internal variable as an approximate reaction coordinate and minimizing energy with respect to all the other internal coordinates. In the exit channel, the DCP was constructed as the minimum energy structures found at the $\mathrm{M}-\mathrm{C}$ distance of $30 \AA$. However, in the case of the entrance channel, the interactions of reactants have very long range effects and we needed around a X-M distance of $100 \AA$ A to define each DCP.

Following on from our previous studies, ${ }^{13-16}$ we have adopted a three transition state model (3TS model). We have explicitly considered an "inner" (tighter) transition state located in the neighborhood of the first-order saddle point and an "outer" (looser) transition state (TS1) controlling the entrance channel and the dissociation transition state.

A straightforward application of the steady-state hypothesis to the reaction, Scheme (1), leads to the 3TS canonical global rate constant:

$$
k_{\text {global }}^{3 \mathrm{TS}}=\frac{k_{1} k_{2} k_{3}}{k_{2} k_{3}+k_{-1}\left(k_{3}+k_{-2}\right)}
$$
levels:

$$
g_{J K}= \begin{cases}2 J+1 & \text { if } K=0 \\ 2(2 J+1) & \text { if } K>0\end{cases}
$$

and $W_{i}\left(E_{i}{ }^{\prime}, 0,0\right)$ includes the sum of active states with $J=K=0$ and energies ranging from the transition state barrier $T S_{i}$ and $E_{i}^{\prime}\left(E_{i}^{\prime}=E-E_{i}(J, K)\right)$.

where $Q_{R}$ represents the product of the partition functions of reactants in which the center of mass motion partition function $\left(2 \pi \mu k_{\mathrm{B}} T / h^{2}\right)^{3 / 2} V$ has been factored out; $T$ is the absolute temperature; $R, k_{\mathrm{B}}$, and $h$ are the gas, Boltzmann and Planck constants, and $\mu$ is the reduced mass. $V_{\max }$ is the largest value among the energy barriers associated with transition structures $\mathrm{TS}_{i}(i=1-3)$. The $W_{i}(E, J)(i=1-3)$ functions, which include reaction symmetry factors, are the sum of states at energy lower than $E$ and angular momentum $J$ corresponding to the different transition structures $\operatorname{TS}_{i}(i=1-3)$. We have approached the

$$
W_{i}(E, J)=\sum_{K=0}^{J} W_{i}(E, J, K)=\sum_{K=0}^{J} g_{J K} W_{i}\left(E_{i}{ }^{\prime}, 0,0\right)
$$
achieved for the different halomethanes will be compared with our previous results of the $\mathrm{M}^{+}(\mathrm{M}=\mathrm{Mg}-\mathrm{Ba})+\mathrm{CH}_{3} \mathrm{~F}^{14}$ reactions. Finally we will characterize the mechanism for the reactions studied by means of the Mulliken population analysis (MPA) and by a topological analysis of the electron density.

\section{A. Energy results}

Fig. 2 depicts the structures of the stationary points on the PESs of the $\mathrm{M}^{+}+\mathrm{CH}_{3} \mathrm{X}(\mathrm{M}=\mathrm{Mg}, \mathrm{Ca}, \mathrm{Sr}, \mathrm{Ba} ; \mathrm{X}=\mathrm{Cl}, \mathrm{Br})$ reactions. The 


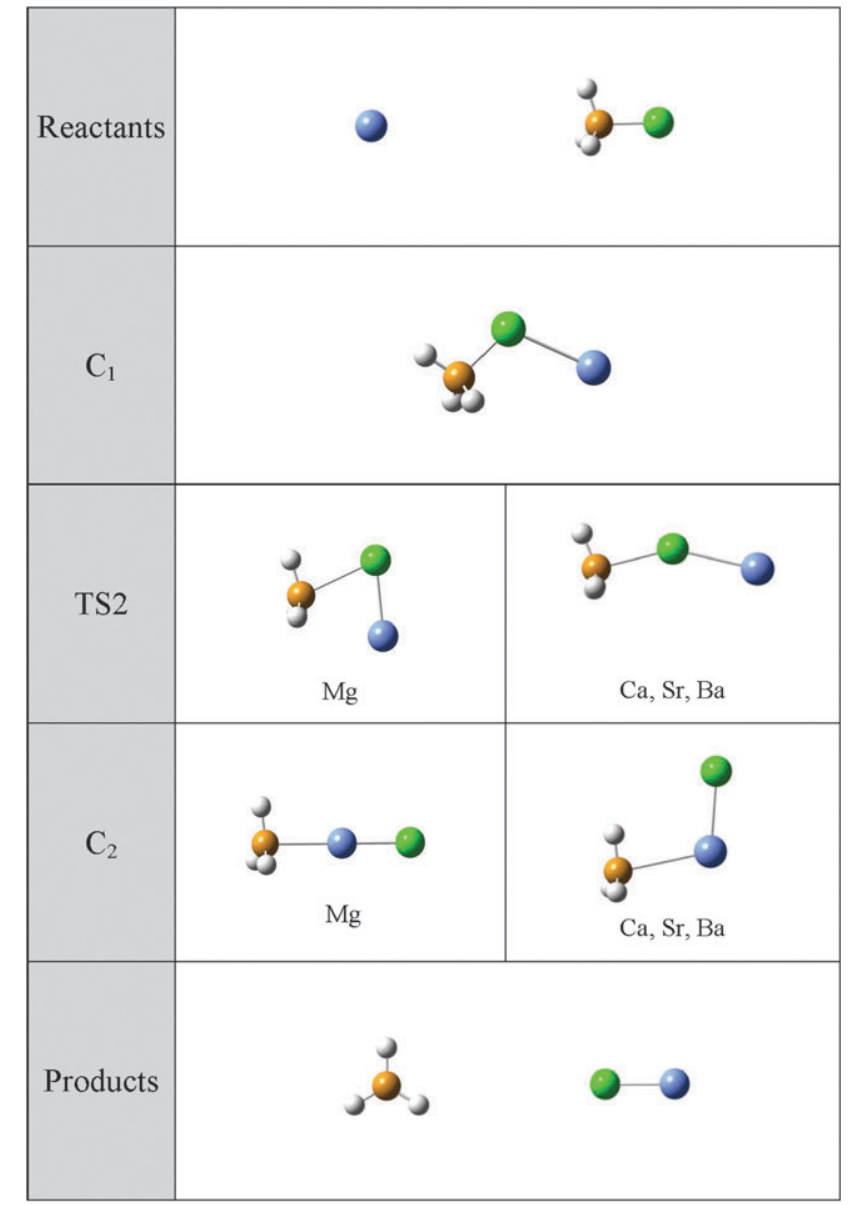

Fig. 2 Structures of the reactants $\left(M^{+}\right.$and $\left.\mathrm{CH}_{3} \mathrm{X}\right)$, intermediates $\left(\mathrm{C}_{1}\right.$ and $\left.\mathrm{C}_{2}\right)$, transition structures (TS2) and products $\left(\mathrm{MX}^{+}\right.$and $\left.\mathrm{CH}_{3}\right)$ of the $\mathrm{M}^{+}+$ $\mathrm{CH}_{3} \mathrm{X}$ reactions $(\mathrm{M}=\mathrm{Mg}, \mathrm{Ca}, \mathrm{Sr}, \mathrm{Ba} ; \mathrm{X}=\mathrm{Cl}, \mathrm{Br})$.

corresponding mPW1K/QZVPP optimized geometrical parameters are given in Table 1.

For all studied reactions, the first step corresponds to the formation of a rather stable encounter complex $\mathrm{C}_{1}$. The interaction potential between reactants is attractive for the whole range of $\mathrm{M} \cdots \mathrm{X}$ distances and no transition structure can be expected in this region of the PES. In all cases, the $\mathrm{C}_{1}$ intermediate has $C_{\mathrm{s}}$ symmetry and exhibits similar geometrical disposition. In this intermediate, the $\mathrm{M}-\mathrm{X}-\mathrm{C}$ angle is clearly distorted from linearity, the values ranging from $113.7^{\circ}$ for the $\mathrm{Mg}^{+}$to $119.8^{\circ}$ for $\mathrm{Ba}^{+}$, in their reactions with $\mathrm{CH}_{3} \mathrm{Cl}$. In the case of the reactions with $\mathrm{CH}_{3} \mathrm{Br}$ the range of the computed values is around $5^{\circ}$ (from $108.3^{\circ}$ in $\mathrm{Mg}^{+}$to $113.5^{\circ}$ for $\mathrm{Ba}^{+}$). Regarding the $\mathrm{C}-\mathrm{X}$ distance, we observe that upon interaction the $\mathrm{C}-\mathrm{Cl}$ distance enlarges from $0.538 \AA$ in the case of $\mathrm{Mg}^{+}$to $0.428 \AA$ for $\mathrm{Ba}^{+}$ with respect to that found in the isolated $\mathrm{CH}_{3} \mathrm{Cl}$ reactant. However, in the bromomethane reactions, the $\mathrm{C}-\mathrm{Br}$ distance is almost identical in the $\mathrm{C}_{1}$ complexes and in isolated $\mathrm{CH}_{3} \mathrm{Br}$. This suggests that the presence of $\mathrm{M}^{+}$does not perturb the geometrical parameters of the $\mathrm{CH}_{3} \mathrm{Br}$ moiety in $\mathrm{CH}_{3} \mathrm{BrM}^{+}$ significantly, thus indicating that an ion-dipole description of bonding is appropriate for this species. As expected the $\mathrm{X}-\mathrm{M}$ bond distance increases when moving downwards in the group, ranging from $2.509 \AA\left(\mathrm{Mg}^{+}\right)$to $3.101 \AA\left(\mathrm{Ba}^{+}\right)$for the reactions with $\mathrm{CH}_{3} \mathrm{Cl}$ and from $2.666 \AA\left(\mathrm{Mg}^{+}\right)$to $3.256 \AA\left(\mathrm{Ba}^{+}\right)$when the reactions are initiated by $\mathrm{CH}_{3} \mathrm{Br}$.

Once the $\mathrm{C}_{1}$ complex is formed, the reaction proceeds through a transition structure TS2. In all cases, the TS2 structures have $C_{\mathrm{s}}$ symmetry; however, for the magnesium monocation, the geometrical parameters are clearly different than those found for the remaining monocations. The $\mathrm{M} \cdots \mathrm{X} \cdots \mathrm{C}$ angle is only $70.8^{\circ}$ for the reaction of $\mathrm{Mg}^{+}$and $\mathrm{CH}_{3} \mathrm{Cl}$ and it increases up to $152.0^{\circ}$ for the reaction of $\mathrm{Ca}^{+}$and $\mathrm{CH}_{3} \mathrm{Cl}$. Consequently, while the $\mathrm{M} \cdots \mathrm{C}$ distance is just $2.671 \AA$ in TS2 for the reaction between $\mathrm{Mg}^{+}$and $\mathrm{CH}_{3} \mathrm{Cl}$ it notably increases up to $4.552 \AA$ for the reaction of $\mathrm{Ca}^{+}$and $\mathrm{CH}_{3} \mathrm{Cl}$. However, despite these different values, in all cases the $\mathrm{M} \cdots \mathrm{C}$ distances are quite large, and thus suggesting that the alkaline-earth metal will interact solely with the halogen. The topological analysis of the electron density reveals that there is no bond critical point between the alkaline-earth metal and the halogen (see Tables 6 and 7 vide infra). In all reactions, the $\mathrm{M} \cdots \mathrm{X}$ distance in TS2 is slightly longer than the bond length in the corresponding isolated $\mathrm{MF}^{+}$product. Consequently, a late transition state should be expected for these processes.

Through transition structure TS2, the intermediate $\mathrm{C}_{1}$ transforms into intermediate $\mathrm{C}_{2}$. This complex has $C_{\mathrm{s}}$ symmetry, except for the $\mathrm{Mg}^{+}+\mathrm{CH}_{3} \mathrm{X}$ reactions where the $\mathrm{C}_{2}$ complex shows $C_{3 v}$ symmetry. As expected the geometrical parameters of the intermediate complex $\mathrm{C}_{2}$ are quite close to that found in isolated products, since in all cases the M $\cdots \mathrm{C}$ distances are large (ranging from $2.3 \AA$ to $3.1 \AA$ ).

Table 2 summarizes the relative (with respect to the separate reactants) adiabatic potential energies $\left(\Delta U_{0}=\Delta U+\mathrm{ZPE}\right)$ and the Gibbs free energies of the intermediates, transition state structures and products of the reactions studied in the present work. In Fig. 3 we show a simplified picture of the PESs for these reactions.

Regarding results in Table 2 as a whole, we observe a similar energy profile for reactions of both halomethanes. Focusing on energetics of the intermediate $\mathrm{C}_{1}$, as expected, the dissociation energies of $\mathrm{M}^{+}-\mathrm{XCH}_{3}$ adducts are quite low (ranging from around $14 \mathrm{kcal} \mathrm{mol}^{-1}$ in $\mathrm{Sr}^{+}$and $\mathrm{Ba}^{+}$reactions to $23 \mathrm{kcal} \mathrm{mol}^{-1}$ in $\mathrm{Mg}^{+}$reactions), thus suggesting weak electrostatic interactions between reactants. As expected the largest values were found for the reactions that include the magnesium monocation and the lowest ones for the reactions of $\mathrm{Sr}^{+}$and $\mathrm{Ba}^{+}$. On the other hand, it should be noted that no significant differences were observed in the energetics of the $\mathrm{C}_{1}$ encounter complexes when bromine is substituted to chlorine in the halomethane molecule. If we compare the energetics of intermediates $\mathrm{C}_{1}$ and $\mathrm{C}_{2}$ we observe that except for the reactions initiated by the magnesium monocation, the intermediate $\mathrm{C}_{2}$ is more stable than the intermediate $\mathrm{C}_{1}$. The energy difference between the $\mathrm{C}_{1}$ and $\mathrm{C}_{2}$ isomers is around $27 \mathrm{kcal} \mathrm{mol}^{-1}$ for the reactions of $\mathrm{Ba}^{+}$. In the reactions of $\mathrm{Ca}^{+}$and $\mathrm{Sr}^{+}$these differences are around 18$19 \mathrm{kcal} \mathrm{mol}^{-1}$ whereas in the reactions of $\mathrm{Mg}^{+} \mathrm{C}_{2}$ becomes less stable than $\mathrm{C}_{1}$. This tendency is closely related to the different
1 
1 Table 1 Geometrical parameters (angstroms and degrees) of the stationary points involved in the reaction of $\mathrm{M}^{+}+\mathrm{CH}_{3} \mathrm{X}(\mathrm{M}=\mathrm{Mg}, \mathrm{Ca}, \mathrm{Sr}, \mathrm{Ba} ; \mathrm{X}=\mathrm{Cl}, \mathrm{Br})$ at the MPW1K/QZVPP level of theory. For the reaction with $\mathrm{CH}_{3} \mathrm{Br}$, values are given in parentheses

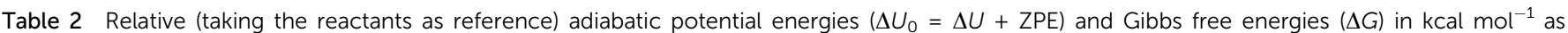

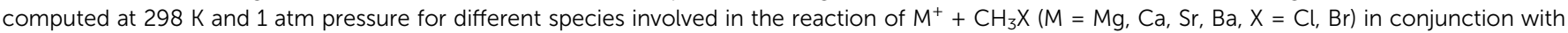
Ahlrichs' QZVPP basis sets at the mPW1K level

40

$\left[\mathrm{CaCH}_{3} \mathrm{X}\right]$

$\left[\mathrm{SrCH}_{3} \mathrm{X}\right]$

$\begin{array}{ll}\mathrm{C}-\mathrm{H} & 1.08 \\ \mathrm{C}-\mathrm{X} & \\ \mathrm{C}-\mathrm{Sr} & \\ \mathrm{Sr}-\mathrm{X} & \\ \mathrm{X}-\mathrm{C}-\mathrm{H} & \\ \mathrm{Sr}-\mathrm{X}-\mathrm{C} & \\ \mathrm{X}-\mathrm{Sr}-\mathrm{C} & - \\ \mathrm{Sr}-\mathrm{C}-\mathrm{H} & - \\ \mathrm{H}-\mathrm{C}-\mathrm{Sr}-\mathrm{X} & \end{array}$

$\left[\mathrm{BaCH}_{3} \mathrm{X}\right]^{+}$

$\begin{array}{ll}\mathrm{C}-\mathrm{H} & 1.084(1.079) \\ \mathrm{C}-\mathrm{X} & 1.365(1.921) \\ \mathrm{C}-\mathrm{Ba} & - \\ \mathrm{Ba}-\mathrm{X} & - \\ \mathrm{X}-\mathrm{C}-\mathrm{H} & 109.1(108.0) \\ \mathrm{Ba}-\mathrm{X}-\mathrm{C} & - \\ \mathrm{X}-\mathrm{Ba}-\mathrm{C} & - \\ \mathrm{Ba}-\mathrm{C}-\mathrm{H} & -\end{array}$

C-H

$\mathrm{C}-\mathrm{X}$

$\mathrm{C}-\mathrm{Ca}$

$\mathrm{X}-\mathrm{C}-\mathrm{H}$

$\mathrm{Ca}-\mathrm{X}-\mathrm{C}$

$\mathrm{X}-\mathrm{Ca}-\mathrm{C}$

$\mathrm{Ca}-\mathrm{C}-\mathrm{H}$

$\mathrm{H}-\mathrm{C}-\mathrm{Ca}-\mathrm{X}$

$\mathrm{H}-\mathrm{C}-\mathrm{Ba}-\mathrm{X}$
1.074 (1.075)

$84.4(84.8)$

1.073

$2.311(2.464)$

-

$-$

$-$

$-$

$456(2.612)$

-

- $\quad-$

$-\quad-$

- $\quad-$

$1.073-$

- -

- $2.587(2.748)$

-

- $\quad-$

- $\quad-$
$\mathrm{C}_{1}$

1.078 (1.079)

1.803 (1.953)

-

2.509 (2.666)

X-C

$\mathrm{Mg}-\mathrm{X}-\mathrm{C}$

$\mathrm{X}-\mathrm{Mg}-\mathrm{C}$

$\mathrm{H}-\mathrm{C}-\mathrm{Mg}-\mathrm{X}$
1.365 (1.921)

$109.1(108.0)$

-

-

-
113.7 (108.3)

-

$0.0(0.0)$

$1.078(1.078)$

1.799 (1.950)

$2.763(2.926)$

$107.9(107.6)$

$117.0(111.4)$

$0.0(0.0)$

1.078 (1.078)

1.795 (1.947)

2.961 (3.126)

105.7 (105.1)

119.6 (113.6)

-

$0.0(0.0)$

1.079 (1.078)

1.793 (1.945)

-

3.101 (3.256)

105.8 (105.2)

119.8 (113.5)

-

$0.0(0.0)$

TS2 $\mathrm{C}_{2}$

1.078 (1.073)

2.413 (2.527)

2.671 (2.622)

$2.188(2.341)$

108.2 (135.6)

70.8 (65.1)

58.55 (60.9)

83.65 (135.6)

$0.0(0.0)$

$1.074(1.075)$

$2.229(2.344)$

4.552()

2.462 (2.612)

$99.9(100.4)$

$152.0(149.6)$

-

$180.0(60.30)$

2.221 (2.329)

$2.630(2.781)$

$98.3(98.9)$

160.7 (156.6)

-

$0.03(-0.1)$

$\mathrm{C}_{2}$

1.082 (1.082)

$2.356(2.356)$

$2.110(2.256)$

-

$180.0(180.0)$

96.8 (96.9)

$0.0(0.0)$

1.081 (1.081)

4.045 (4.209)

2.727 (2.725)

2.333 (2.487)

40.4 (38.1)

105.9 (107.6)

$180.0(0.0)$

1.081 (1.081)

4.006 (4.169)

2.897 (2.895)

2.476 (2.632)

-

$46.0(43.5)$

$96.1(97.8)$

$83.2(83.7)$

$0.0(0.0)$

1.076 (1.076)

$2.084(2.184)$

-

2.755 (2.911)

101.0 (101.9)

$133.0(130.9)$

-

$0.0(0.0)$
$1.079(1.080)$

3.993 (4.144)

3.096 (3.091)

$2.607(2.769)$

-

$50.8(48.2)$

$96.7(89.8)$

$83.0(83.3)$

$0.0(0.0)$

$\mathrm{CH}_{3} \quad \mathrm{MX}$

$\begin{array}{ll}1.073 & - \\ - & - \\ - & - \\ - & 1.702(2.240) \\ - & - \\ - & - \\ - & -\end{array}$

5

\begin{tabular}{|c|c|c|c|c|c|c|c|c|c|c|c|}
\hline \multirow[b]{2}{*}{$\mathbf{M}$} & \multirow[b]{2}{*}{$\mathrm{X}$} & \multicolumn{2}{|c|}{$\underline{\mathbf{M}^{+}+\mathrm{CH}_{3} \mathrm{X}}$} & \multicolumn{2}{|l|}{$\mathrm{C}_{1}$} & \multicolumn{2}{|l|}{ TS2 } & \multicolumn{2}{|l|}{$\mathrm{C}_{2}$} & \multicolumn{2}{|c|}{$\mathrm{MCl}^{+}+\mathrm{CH}_{3}$} \\
\hline & & $\Delta U_{0}$ & $\Delta G$ & $\Delta U_{0}$ & $\Delta G$ & $\Delta U_{0}$ & $\Delta G$ & $\Delta U_{0}$ & $\Delta G$ & $\Delta U_{0}$ & $\Delta G$ \\
\hline \multirow[t]{2}{*}{$\mathrm{Mg}$} & $\mathrm{Cl}$ & 0.0 & 0.0 & -21.66 & -16.69 & 11.77 & 17.23 & -18.68 & -13.59 & 8.13 & 6.59 \\
\hline & $\mathrm{Br}$ & 0.0 & 0.0 & -22.73 & -17.74 & 9.53 & 15.20 & -20.32 & -15.17 & 5.80 & 4.28 \\
\hline \multirow[t]{2}{*}{$\mathrm{Ca}$} & $\mathrm{Cl}$ & 0.0 & 0.0 & -17.41 & -12.69 & -4.14 & -0.02 & -36.57 & -32.69 & -23.04 & -24.64 \\
\hline & $\mathrm{Br}$ & 0.0 & 0.0 & -17.64 & -12.91 & -7.35 & -8.55 & -36.24 & -32.24 & -22.63 & -24.21 \\
\hline \multirow[t]{2}{*}{$\mathrm{Sr}$} & $\mathrm{Cl}$ & 0.0 & 0.0 & -14.13 & -9.67 & -1.26 & 2.22 & -33.02 & -29.04 & -21.85 & -23.48 \\
\hline & $\mathrm{Br}$ & 0.0 & 0.0 & -14.26 & -9.72 & -4.73 & -1.17 & -33.01 & -29.00 & -21.72 & -23.30 \\
\hline \multirow[t]{2}{*}{$\mathrm{Ba}$} & $\mathrm{Cl}$ & 0.0 & 0.0 & -14.16 & -9.70 & -6.11 & -1.63 & -41.66 & -37.77 & -33.01 & -34.68 \\
\hline & $\mathrm{Br}$ & 0.0 & 0.0 & -14.29 & -9.79 & -10.30 & -5.61 & -41.61 & -37.64 & -32.80 & -34.43 \\
\hline
\end{tabular}

values of halogen affinity shown by the alkaline-earth monocations. At the mPW1K/QZVPP level, our predicted chlorine/ bromine affinity for $\mathrm{Mg}^{+}, \mathrm{Ca}^{+} \mathrm{Sr}^{+}$and $\mathrm{Ba}^{+}$are, respectively, $70.51 / 62.05 \mathrm{kcal} \mathrm{mol}^{-1}, 101.67 / 90.48 \mathrm{kcal} \mathrm{mol}^{-1}, 100.49 / 89.57$ and $111.64 / 100.66 \mathrm{kcal} \mathrm{mol}^{-1}$.
Regarding energetics of the transition structure TS2, it can be seen that the transition structures for the insertion of $\mathrm{M}^{+}$ into the carbon-halogen bond are below the entrance channel, except for $\mathrm{Mg}^{+}$. In the latter case, the transition structures are well above the reactants $\left(\Delta U_{0}=11.77 \mathrm{kcal} \mathrm{mol}^{-1}\right.$ for the reaction 


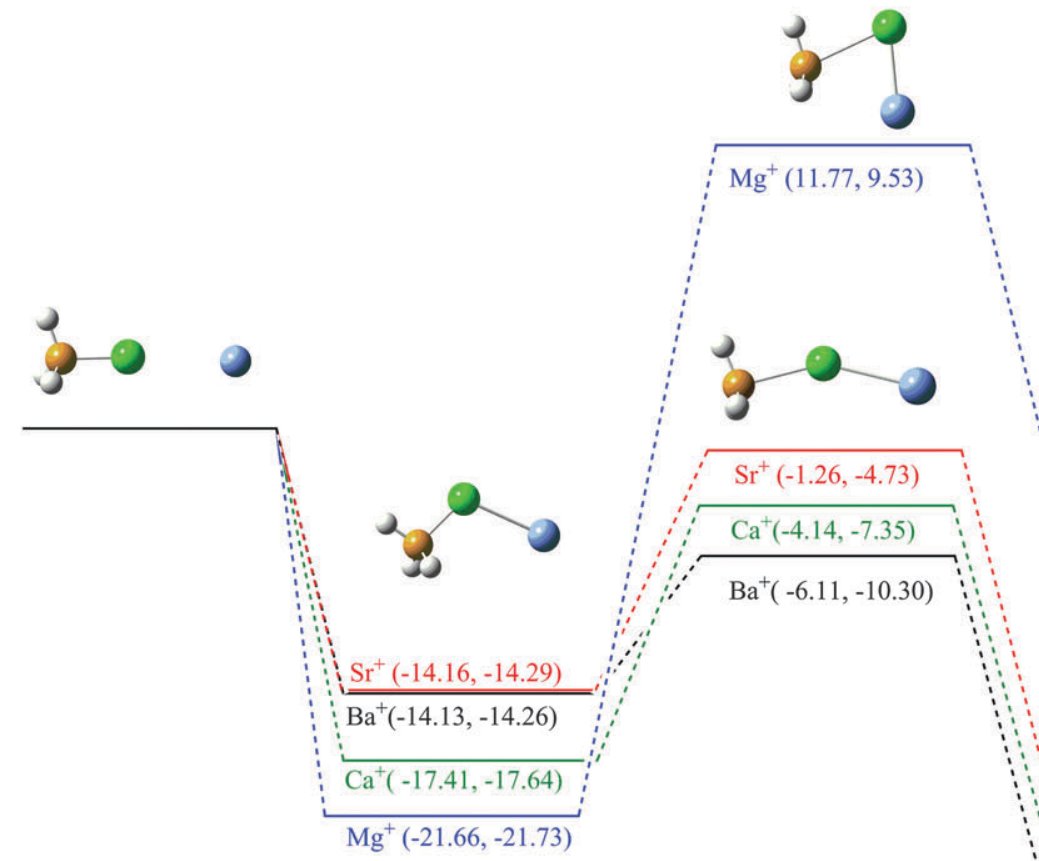

with $\mathrm{CH}_{3} \mathrm{Cl}$ and $\Delta U_{0}=9.53 \mathrm{kcal} \mathrm{mol}^{-1}$ for the reaction with $\mathrm{CH}_{3} \mathrm{Br}$ ). Furthermore, in these reactions involving $\mathrm{Mg}^{+}$, the transition state connecting $\mathrm{C}_{1}$ and $\mathrm{C}_{2}$ is much higher in energy than reactants. Consequently, the thermal activation of both chloro- and bromomethane will be extremely improbable and the reactions should not progress beyond the $\mathrm{C}_{1}$ adduct complex. It should be also noted that when bromine replaces chlorine in the reactions, the TS2 energy decreases for all reactions (from $2.24 \mathrm{kcal} \mathrm{mol}^{-1} \mathrm{in}^{\mathrm{Mg}^{+}}$ reactions to $4.19 \mathrm{kcal} \mathrm{mol}^{-1}$ in $\mathrm{Ba}^{+}$reactions). This behavior is related to the different polarities of the $\mathrm{C}-\mathrm{X}$ bond in $\mathrm{CH}_{3} \mathrm{Cl}$ and $\mathrm{CH}_{3} \mathrm{Br}$.

The processes of formation of products are clearly exothermic and exergonic, except for the reactions of $\mathrm{Mg}^{+}$. As expected the most exothermic (and exergonic) reactions are those initiated by the barium monocation $\left(\Delta U_{0}=-34.68 \mathrm{kcal} \mathrm{mol}^{-1}\right.$, for its reaction with $\mathrm{CH}_{3} \mathrm{Cl}$ and $\Delta U_{0}=-34.43 \mathrm{kcal} \mathrm{mol}^{-1}$ for the $\mathrm{CH}_{3} \mathrm{Br}$ one). On the other hand, the reactions of $\mathrm{Mg}^{+}$with either $\mathrm{CH}_{3} \mathrm{Cl}$ or $\mathrm{CH}_{3} \mathrm{Br}$ are clearly endothermic and endergonic processes $\left(\Delta U_{0}=8.13 \mathrm{kcal}\right.$ $\mathrm{mol}^{-1}$, for the reaction with $\mathrm{CH}_{3} \mathrm{Cl}$ and $\Delta U_{0}=5.80 \mathrm{kcal} \mathrm{mol}^{-1}$ for $\mathrm{CH}_{3} \mathrm{Br}$ ). These results, together with the relatively high energetic barrier found, suggest that these reactions are not expected to proceed beyond the intermediate $\mathrm{C}_{1}$. Again, the exo- or endothermicity of the processes is directly related to the values of the chlorine/ bromine affinity shown by the alkaline-earth monocations.

With regard to the relative adiabatic potential energies $\left(\Delta U_{0}=\Delta U+\mathrm{ZPE}\right)$ and Gibbs free energies $(\Delta G)$ shown in Table 2, it can be seen that when the entropic factor is taken into account the products slightly stabilize (by around 1-2 kcal $\mathrm{mol}^{-1}$ ) whereas intermediates and transition structures destabilize (by around 3-6 kcal mol${ }^{-1}$ ).

\section{B. Kinetics results}

Tables 3 and 4 summarize the calculated thermal rate constants, at a wide range of temperatures, for the reactions considered in the present work. The corresponding Arrhenius plots are shown in Fig. 4 and 5. In both figures and tables we have collected the values of the global (2TS) rate constants and their main limiting components, $k_{\text {outer }}, k_{\text {inner }}$ and $k_{\text {exit }}$, in order to analyze the role played by the "outer", "inner" and "exit" transition states in the global processes. As mentioned above, $k_{\text {inner }}$ describes the limiting behavior of the global rate constant when the dominant bottleneck for the reaction is provided by the tighter "inner" transition state $\left(W_{1}(E, J), W_{3}(E, J)\right.$, 》 $W_{2}(E, J)$ ). When the looser "outer" transition state (in the entrance channel) controls the rate constant we obtain $k_{\text {outer }}$ $\left(W_{2}(E, J), W_{3}(E, J), \gg W_{1}(E, J)\right)$. Finally $k_{\text {exit }}$ describes the behavior of the rate constant when the exit dissociation channel controls the process. 

$\times \times \times \times \times \times \times \times \times \times$

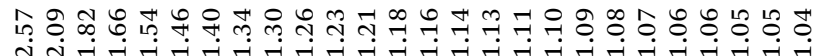
\& \& \& \& \& \& \& \& \& \& \& \& \& \& \& \& \& \& \& o \& \& \& o \& o $\times \times \times \times \times \times \times \times \times \times \times \times \times \times \times \times \times \times \times \times \times \times \times \times \times \times$

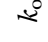

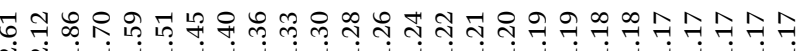

항 항 b

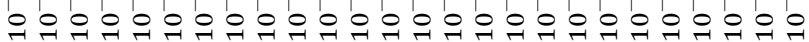
$\times \times \times \times \times \times \times \times \times \times \times \times \times \times \times \times \times \times \times \times \times \times \times \times \times$

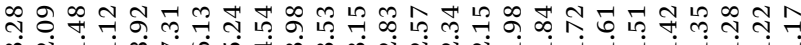

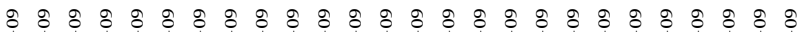

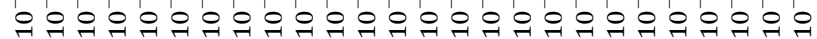

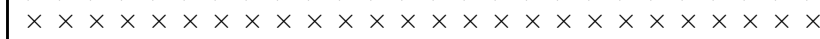

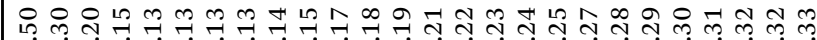

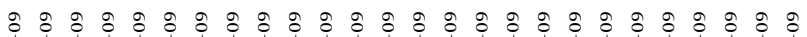

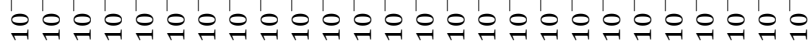

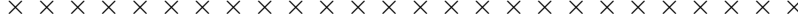

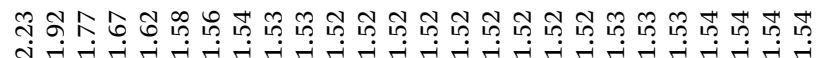

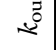
\& \& \& \& \& \& \& \& \& \& \& \& \& \& \& \& \& \& \& \& \& \& \& $\infty$ \&

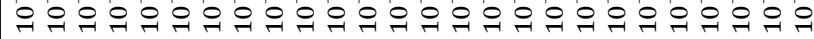
$\times \times \times \times \times \times \times \times \times \times \times \times \times \times \times \times \times \times \times \times \times \times \times \times \times$

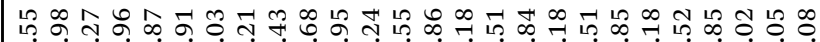

\& \& \& \& \& \& \& \& \& \& \& \& \& \& \& 융ㅇㅇㅇㅇㅇㅇㅇㅇㅇ

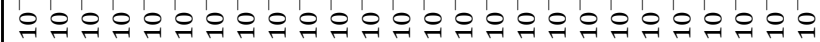
$\times \times \times \times \times \times \times \times \times \times \times \times \times \times \times \times \times \times \times \times \times \times \times \times$

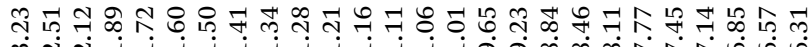
我

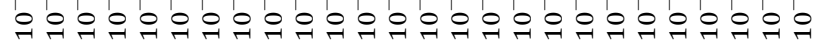
$\times \times \times \times \times \times \times \times \times \times \times \times \times \times \times \times \times \times \times \times \times \times \times \times \times \times$

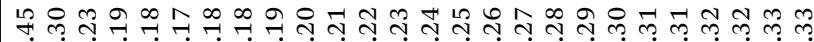
$\times \times \times \times \times \times \times \times \times \times \times \times \times \times \times \times \times \times \times \times \times \times \times \times \times \times$

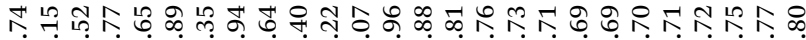

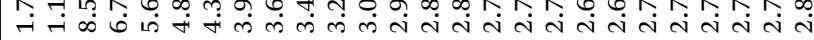

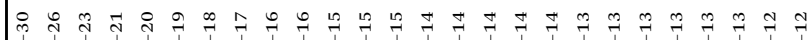

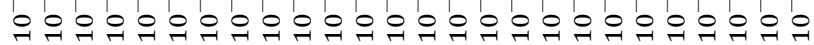
$\times \times \times \times \times \times \times \times \times \times \times \times \times \times \times \times \times \times \times \times \times \times \times \times \times \times$

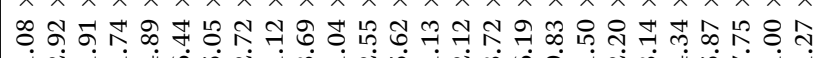

ن ส의

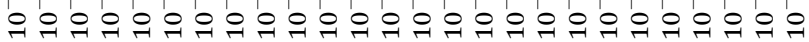
$\times \times \times \times \times \times \times \times \times \times \times \times \times \times \times \times \times \times \times \times \times \times \times \times \times \times$

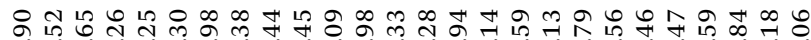
ம்

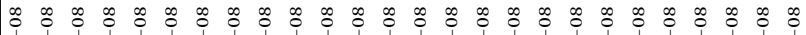

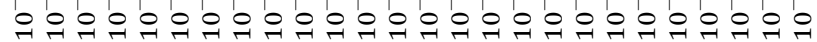
$\times \times \times \times \times \times \times \times \times \times \times \times \times \times \times \times \times \times \times \times \times \times \times \times \times x$

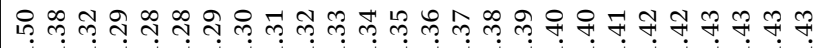



$x \times x \times x \times x \times x \times x \times x \times x \times x \times x \times x \times x \times x \times$ 용 \&

ن 용ㅇㅇㅇㅇㅇㅇㅇㅇㅇㅇㅇㅇㅇㅇㅇㅇㅇㅇㅇㅇㅇㅇㅇㅇㅇㅇㅢ

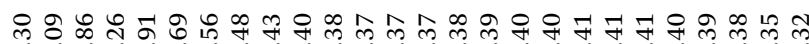

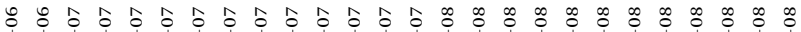

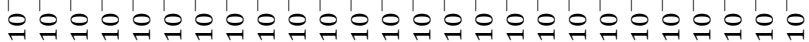
$\times \times \times \times \times \times \times \times \times \times \times \times \times \times \times \times \times \times \times \times \times \times \times \times \times$

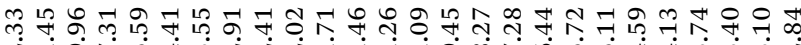

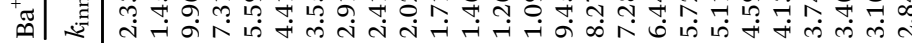

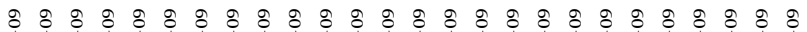

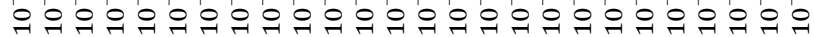
$\mathrm{K} \times \times \times \times \times \times \times \times \times \times \times \times \times \times \times \times \times \times \times \times \times \times \times \times \times$

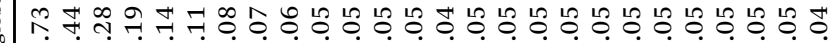

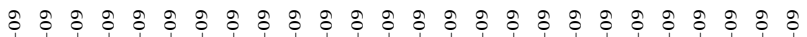

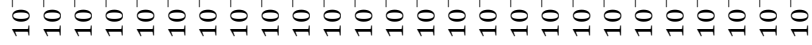

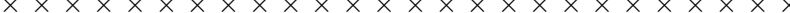

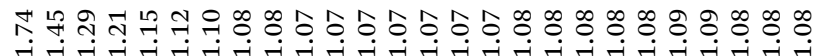

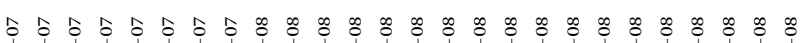

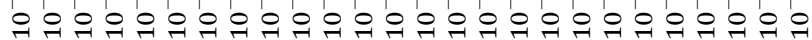
$\times \times \times \times \times \times \times \times \times \times \times \times \times \times \times \times \times \times \times \times \times \times \times \times \times$

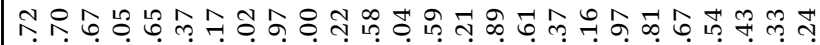

ம ल

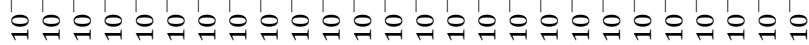
$\times \times \times \times \times \times \times \times \times \times \times \times \times \times \times \times \times \times \times \times \times \times \times \times \times \times$

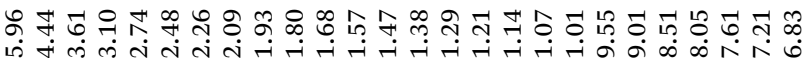
車

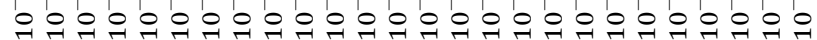
$\times \times \times \times \times \times \times \times \times \times \times \times \times \times \times \times \times \times \times \times \times \times \times \times$

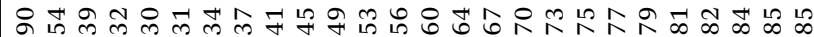

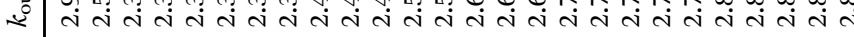

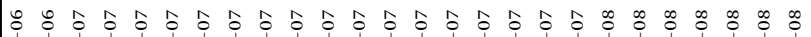

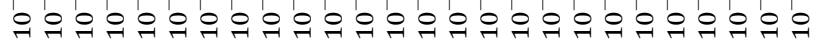
$\times \times \times \times \times \times \times \times \times \times \times \times \times \times \times \times \times \times \times \times \times \times \times \times \times \times$

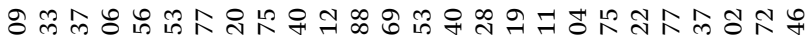

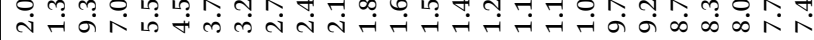

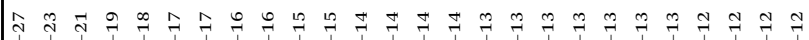

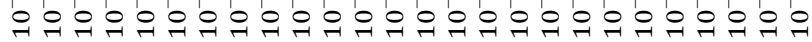
$\times \times \times \times \times \times \times \times \times \times \times \times \times \times \times \times \times \times \times \times \times \times \times \times \times$ 누 तิ

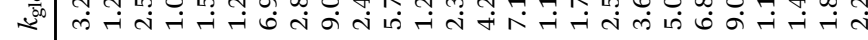

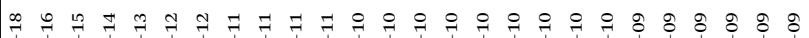

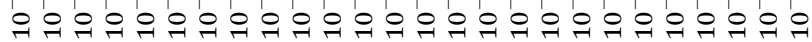
$x \times \times \times \times \times \times \times \times \times \times \times \times \times \times \times \times \times \times \times \times \times \times \times \times \times$

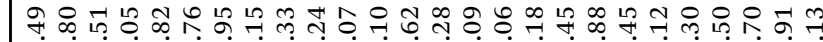

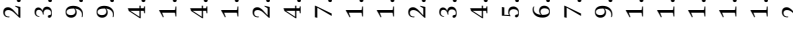
㑒

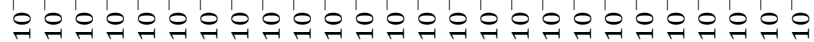
$\times \times \times \times \times \times \times \times \times \times \times \times \times \times \times \times \times \times \times \times \times \times \times \times \times \times$

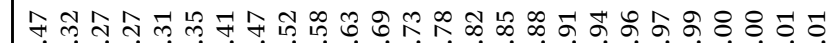
ن तิ

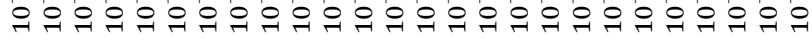
$\times \times \times \times \times \times \times \times \times \times \times \times \times \times \times \times \times \times \times \times \times \times \times \times$

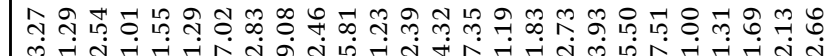



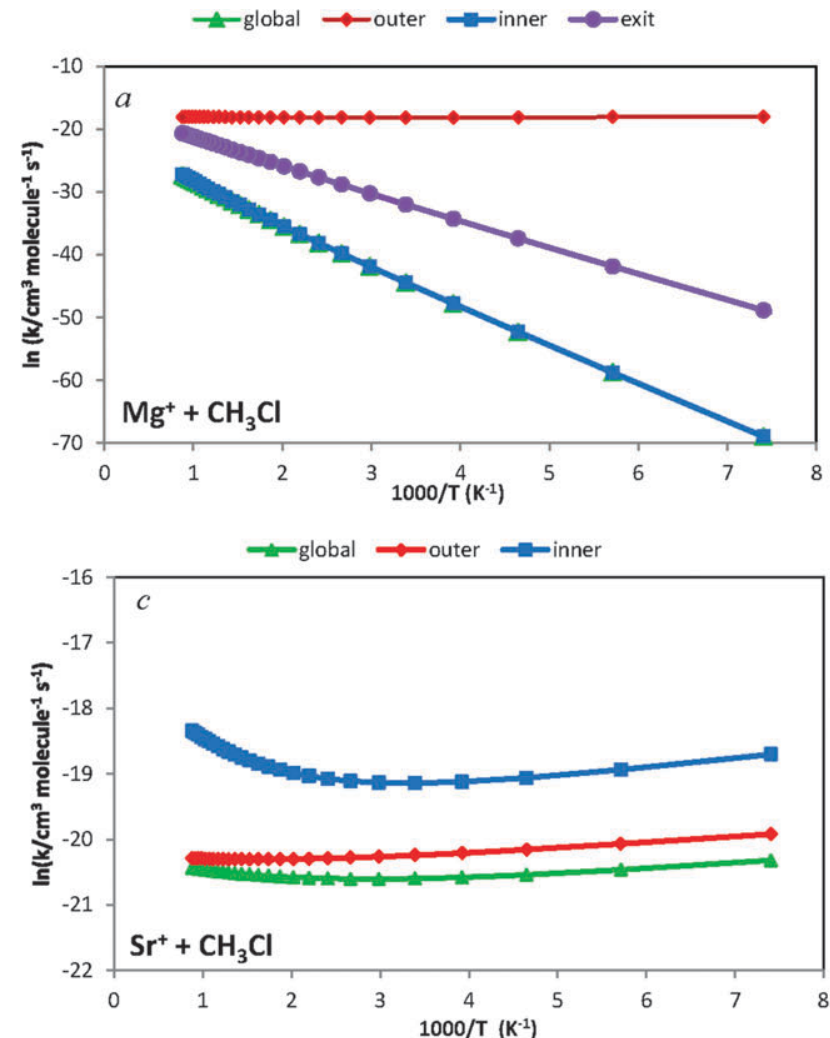
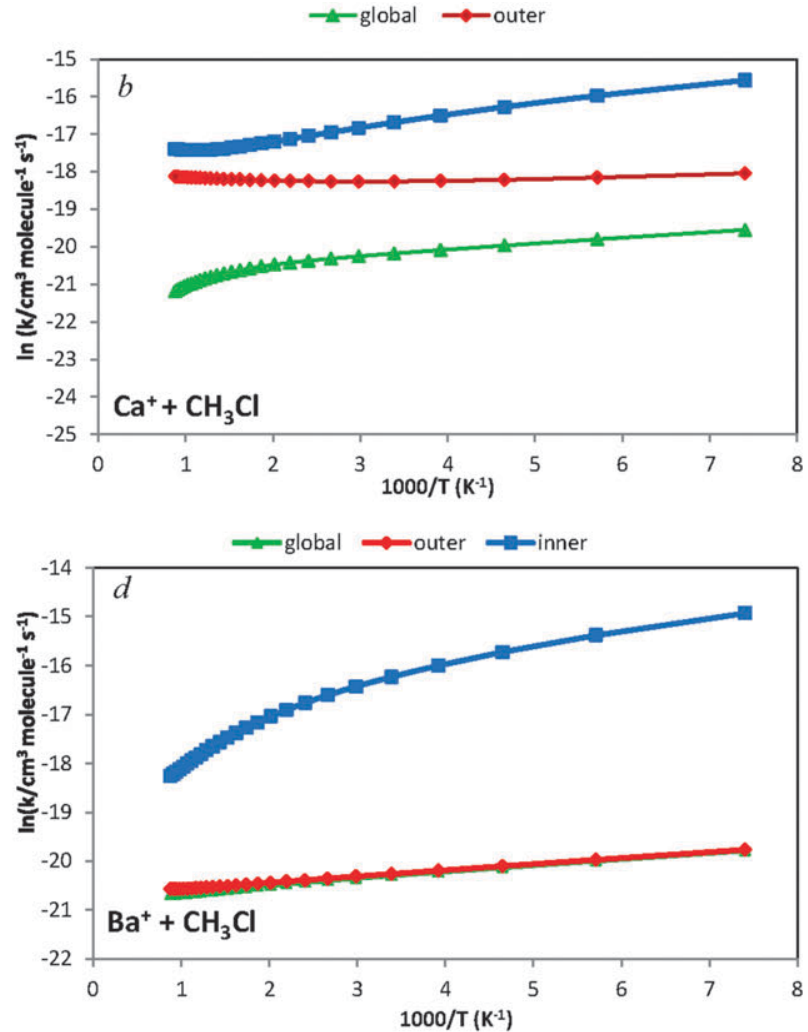

1

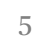

10

Fig. 4 Arrhenius plots for the rate constants of the $\mathrm{M}^{+}+\mathrm{CH}_{3} \mathrm{Cl}$ reactions $(\mathrm{M}=\mathrm{Mg}, \mathrm{Ca}, \mathrm{Sr}, \mathrm{Ba}) ; k_{\text {global, }}$ (green), $k_{\text {inner }}(\mathrm{blue}), k_{\text {outer }}$ (red), and $k_{\text {exit }}$ (gray).
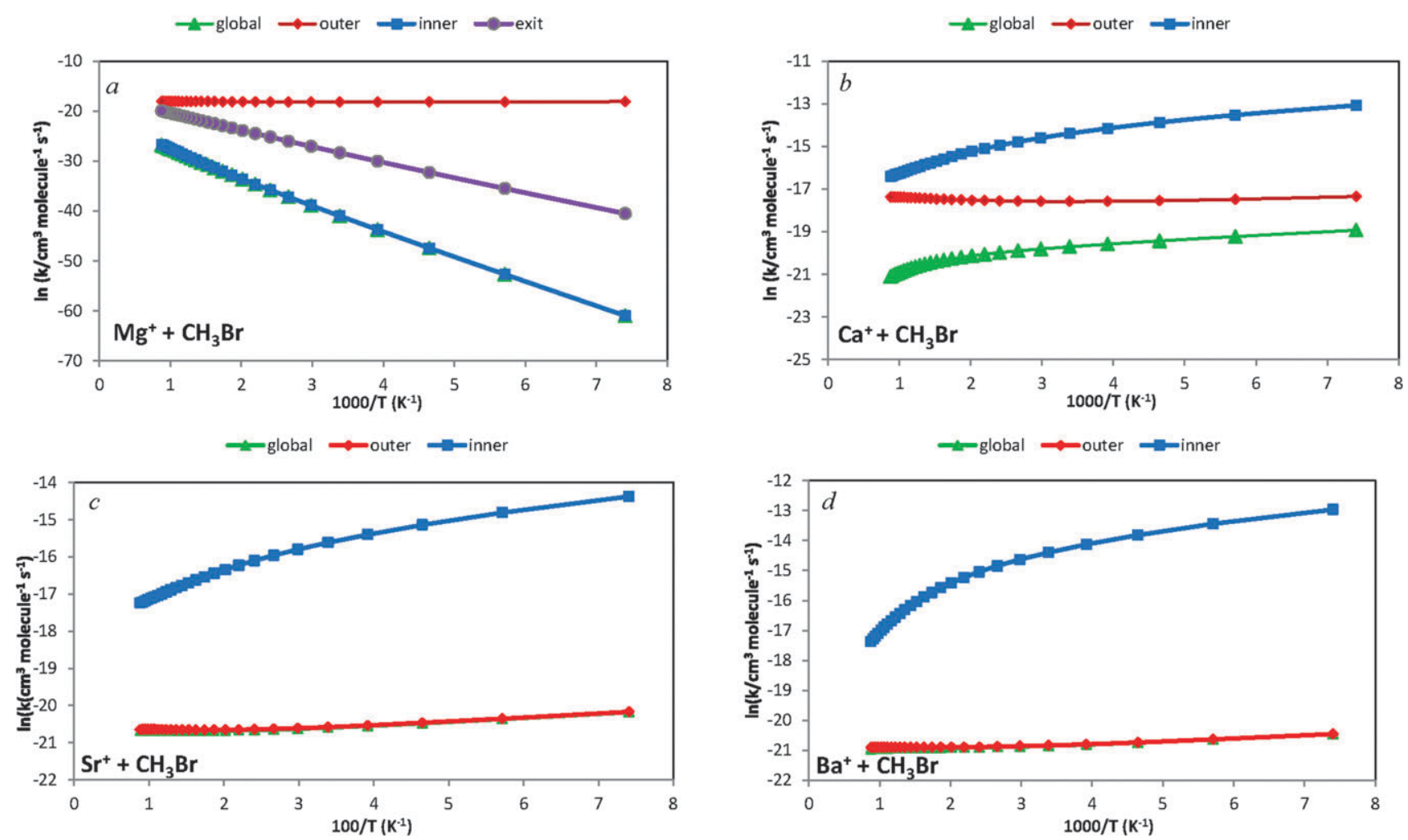

Fig. 5 Arrhenius plots for the rate constants of the $\mathrm{M}^{+}+\mathrm{CH}_{3} \mathrm{Br}$ reactions $(\mathrm{M}=\mathrm{Mg}, \mathrm{Ca}, \mathrm{Sr}, \mathrm{Ba}) ; k_{\text {global, }}$ (green), $k_{\text {inner }}(\mathrm{blue}), k_{\text {outer }}\left(\right.$ red), and $k_{\text {exit }}$ (gray). 
As we have already noted, the reactions between the magnesium monocation and either $\mathrm{CH}_{3} \mathrm{Cl}$ or $\mathrm{CH}_{3} \mathrm{Br}$ are endothermic $\left(\Delta U_{0}=8.13 / 5.80 \mathrm{kcal} \mathrm{mol}^{-1}\right)$ and have significant energetic barriers $\left(\Delta U_{0}=11.77 / 9.53 \mathrm{kcal} \mathrm{mol}^{-1}\right)$. Thus the production of $\mathrm{MgCl}^{+} / \mathrm{MgBr}^{+}$will be, a priori, likely precluded by this unfavorable thermochemistry. However in both reactions the endothermicity has a lower value than the energetic barrier, thus it should be expected that the exit channel does not play any significant role in the kinetics of these processes. In order to confirm this assertion,

10 we have computed the "exit" component of the rate coefficients for these reactions. The Arrhenius plots for the reactions between $\mathrm{Mg}^{+}$ and $\mathrm{CH}_{3} \mathrm{Cl} / \mathrm{CH}_{3} \mathrm{Br}$ (inset a in Fig. 4 and 5) show the typical picture of these processes with positive activation barriers. As expected, both the "outer" and "exit" components of the rate constant are 15 very large compared to that found for the "inner" component, thus making the rate constant for the global process independent of both the entrance and exit channels. Note that in such conditions the 3TS global rate constant (eqn (9)) reduces to the 2TS global rate constant (eqn (10)). At $295 \mathrm{~K}$ our predicted rate coefficients for the reactions of $\mathrm{Mg}^{+}$with $\mathrm{CH}_{3} \mathrm{Cl} / \mathrm{CH}_{3} \mathrm{Br}$ have very low values, $k_{\text {global }}=$ $4.89 \times 10^{-20} / 4.89 \times 10^{-18} \mathrm{~cm}^{3}$ molecule ${ }^{-1} \mathrm{~s}^{-1}$, thus suggesting that the global processes cannot take place and the reactions will not proceed beyond the encounter complex $\mathrm{CH}_{3} \mathrm{XMg}^{+}$.

If we compare the results obtained for the two halomethanes considered in our study, we observe that the reaction will be faster when it involves $\mathrm{CH}_{3} \mathrm{Br}$ rather than $\mathrm{CH}_{3} \mathrm{Cl}$. This result is mainly attributable to the lower energy barrier observed in the reaction including $\mathrm{CH}_{3} \mathrm{Br} 9.53 \mathrm{kcal} \mathrm{mol}^{-1}\left(11.77 \mathrm{kcal} \mathrm{mol}^{-1}\right.$ for $\left.\mathrm{CH}_{3} \mathrm{Cl}\right)$.

30 Let us now briefly make a comparison of these results and those obtained for the reaction of $\mathrm{Mg}^{+}$with $\mathrm{CH}_{3} \mathrm{~F} .{ }^{14}$ The main difference concerns the implication of the exit channel in the control of the global reaction. Whereas in the reaction of $\mathrm{Mg}^{+}$ with $\mathrm{CH}_{3} \mathrm{~F}$, the products were located slightly higher in energy than the TS2 transitions structure, the opposite occurs in the reactions of either $\mathrm{CH}_{3} \mathrm{Cl}$ or $\mathrm{CH}_{3} \mathrm{Br}$. Thus, the dissociation channel will play a much more important role in the reaction of $\mathrm{CH}_{3} \mathrm{~F}$ than in the reactions studied here.

In contrast to the reactions of the magnesium monocation, 40 the Arrhenius plots for the $\mathrm{Ca}^{+}+\mathrm{CH}_{3} \mathrm{Cl} / \mathrm{CH}_{3} \mathrm{Br}$ reactions (inset b in Fig. 4 and 5) show the typical behavior found in barrierless processes. The global and "inner" rate constants decrease as the temperature increases and the "outer" component is practically constant in the whole range of temperatures considered. As constant is mainly controlled by the "outer" bottleneck especially at low temperatures. As the temperature increases both the "inner" and "outer" components became similar in importance. Our computed rate coefficients at $295 \mathrm{~K}$ are $k_{\text {global }}=1.72 \times 10^{-9} / 2.7410^{-9} \mathrm{~cm}^{3}$ molecule ${ }^{-1} \mathrm{~s}^{-1}$.

In the reactions of the calcium monocation the magnitude of the rate constants increases as we move from fluoromethane to bromomethane as a direct consequence of lowering of the energy barrier of the TS2 transition structure.

From Fig. 4 and 5 (insets $\mathrm{c}$ and d) we can infer that, for the reactions of $\mathrm{Sr}^{+}$and $\mathrm{Ba}^{+}$with $\mathrm{CH}_{3} \mathrm{Cl} / \mathrm{CH}_{3} \mathrm{Br}$, the global constants and their limiting components change with temperature as for prototypical barrierless processes. The kinetics of these reactions is mainly controlled by the "outer" bottleneck in the whole range of temperatures considered in our study. In the reactions of $\mathrm{Sr}^{+}$and $\mathrm{CH}_{3} \mathrm{Cl} / \mathrm{CH}_{3} \mathrm{Br}$, the rate coefficients as computed at $295 \mathrm{~K}$ were $k_{\text {global }}=1.13 \times 10^{-9} / 1.14 \times 10^{-9} \mathrm{~cm}^{3}$ molecule ${ }^{-1} \mathrm{~s}^{-1}$. At $295 \mathrm{~K}$ our kinetics constants for the reactions initiated by the barium monocation were $k_{\text {global }}=1.54 \times$ $10^{-9} / 8.87 \times 10^{-10} \mathrm{~cm}^{3}$ molecule ${ }^{-1} \mathrm{~s}^{-1}$.

We should point out that in the equivalent reactions between $\mathrm{Sr}^{+}$and $\mathrm{Ba}^{+}$with $\mathrm{CH}_{3} \mathrm{~F}^{14}$ the dominant contribution to the global constant was the "inner" component, except at very high temperatures where the "outer" bottleneck became competitive. This different behavior is reasonable since the energy of the TS2 transition structure is clearly below the reactants when both chlorine and bromine substitute fluorine in the halomethane and, for these reactions, the "outer" bottleneck fully controls the global rate constants.

With regard to the efficiencies $\left(k_{\text {global }} / k_{\text {outer }}\right)$, we observe that strontium and barium monocations show a much more active chemistry than the magnesium monocation. The efficiencies are close to unity in the reactions of $\mathrm{Sr}^{+}$and $\mathrm{Ba}^{+}$with $\mathrm{CH}_{3} \mathrm{Br}$ whereas in the reaction of $\mathrm{Mg}^{+}$with $\mathrm{CH}_{3} \mathrm{Cl}$ the efficiency, at 295 $\mathrm{K}$, is as small as $3.82 \times 10^{-12}$. This behavior also agrees with our previous findings when studying the $\mathrm{M}^{+}+\mathrm{CH}_{3}$ F reactions. ${ }^{14}$

\section{Reaction mechanisms}

The reactions between metal monocations and halomethanes may proceed mainly through two different mechanisms, ${ }^{38,39}$ namely single-electron transfer (SET) or "harpoon"-like mechanism:

$$
\begin{aligned}
\mathrm{M}^{\bullet+}+\mathrm{X}-\mathrm{CH}_{3} \rightarrow \mathrm{M}^{+} & \cdots \mathrm{X}-\mathrm{CH}_{3}^{\bullet} \rightarrow \mathrm{TS} 2 \rightarrow \mathrm{M}^{2+} \cdots \mathrm{X}^{-}-\mathrm{CH}_{3} \bullet \\
\rightarrow & \mathrm{MX}^{+}+\mathrm{CH}_{3}^{\bullet}
\end{aligned}
$$

and oxidative addition mechanism:

$$
\mathrm{M}^{\bullet+}+\mathrm{X}-\mathrm{CH}_{3} \rightarrow \mathrm{X}-\mathrm{M}^{+}-\mathrm{CH}_{3}^{\bullet} \rightarrow \mathrm{MX}^{+}+\mathrm{CH}_{3}^{\bullet}
$$

The results of our previous studies concerning the reactions of different monocations with fluoromethane ${ }^{13-16}$ suggested that the mechanism of the reaction could be determined by the structural disposition of the "inner" transition structure. In such a way, linear arrangements of the TS2 transition structure favor SET "harpoon"-like mechanisms whereas the oxidative addition mechanism could play an important role in reactions with ring arrangements of the TS2 transition state structures. It should be noted that even though an insertion-elimination mechanism always requires a nonlinear transition state structure the inverse is not true, and a nonlinear transition state structure does not always imply the oxidative mechanism.

In the "harpoon-like mechanism another interesting point concerns the existence or not of an inverse relationship between efficiency of a reaction and the Second Ionization Energy (SIE) of the metal atom. From our previous studies ${ }^{13-}$ 16 we concluded that in reactions controlled by the "outer" transition state, no correlation between efficiency and SIE should be expected, and thus the SIE-rate coefficient 
Table 5 Partial charges (au) and spin densities of alkaline earth metal, halogen (parentheses), and $\mathrm{CH}_{3}$ [brackets] according to Mulliken Population Analysis (MPA) at the MPW1K/QZVPP level

\section{$\mathrm{M}(\mathrm{Cl})\left[\mathrm{CH}_{3}\right]^{a}$}

\begin{tabular}{lllll}
\hline & \multicolumn{2}{l}{ Partial charge } & & \\
\cline { 2 - 5 } & $\mathrm{Mg}^{+}$ & $\mathrm{Ca}^{+}$ & $\mathrm{Sr}^{+}$ & $\mathrm{Ba}^{+}$ \\
\hline $\mathrm{C}_{1}$ & $0.778(-0.094)[0.316]$ & $0.825(-0.125)[0.300]$ & $0.851(-0.140)[0.289]$ & $0.861(-0.146)[0.285]$ \\
TS2 & $0.985(-0.296)[0.311]$ & $1.143(-0.367)[0.224]$ & $1.158(-0.370)[0.212]$ & $1.179(-0.335)[0.156]$ \\
$\mathrm{C}_{2}$ & $1.197(-0.414)[0.217]$ & $1.362(-0.500)[0.138]$ & $1.399(-0.526)[0.127]$ & $1.438(-0.551)[0.113]$
\end{tabular}

\begin{tabular}{lllll}
\hline & \multicolumn{2}{l}{ Spin density } & & \\
\cline { 2 - 5 } & $\mathrm{Mg}^{+}$ & $\mathrm{Ca}^{+}$ & $\mathrm{Sr}^{+}$ & $\mathrm{Ba}^{+}$ \\
\hline $\mathrm{C}_{1}$ & $0.972(0.023)[0.005]$ & $0.997(-0.003)[0.006]$ & $0.998(-0.005)[0.007]$ & $1.003(-0.006)[0.003]$ \\
TS2 & $0.548(0.070)[0.382]$ & $0.554(-0.069)[0.515]$ & $0.561(-0.067)[0.506]$ & $0.582(-0.014)[0.432]$ \\
$\mathrm{C}_{2}$ & $0.128(0.033)[0.839]$ & $0.093(0.0006)[0.906]$ & $0.083(-0.001)[0.918]$ & $0.079(-0.001)[0.922]$ \\
\hline
\end{tabular}

$\mathrm{M}(\mathrm{Br})\left[\mathrm{CH}_{3}\right]^{b}$

\begin{tabular}{lllll}
\hline & Partial charge & & \\
\cline { 2 - 5 } & $\mathrm{Mg}^{+}$ & $\mathrm{Ca}^{+}$ & $\mathrm{Sr}^{+}$ & $\mathrm{Ba}^{+}$ \\
\hline $\mathrm{C}_{1}$ & $0.722(0.012)[0.266]$ & $0.778(-0.030)[0.252]$ & $0.806(-0.051)[0.245]$ & $0.829(-0.068)[0.239]$ \\
TS2 & $0.888(-0.146)[0.258]$ & $1.088(-0.277)[0.189]$ & $1.099(-0.279)[0.180]$ & $1.118(-0.241)[0.123]$ \\
$\mathrm{C}_{2}$ & $1.075(-0.289)[0.214]$ & $1.257(-0.396)[0.139]$ & $1.301(-0.430)[0.129]$ & $1.349(-0.464)[0.115]$
\end{tabular}

\begin{tabular}{lllll}
\hline \multicolumn{2}{c}{ Spin density } & & \\
\cline { 2 - 5 } & $\mathrm{Mg}^{+}$ & $\mathrm{Ca}^{+}$ & $\mathrm{Sr}^{+}$ & $\mathrm{Ba}^{+}$ \\
\hline $\mathrm{C}_{1}$ & $0.955(0.043)[0.002]$ & $0.994(0.0002)[0.004]$ & $0.994(-0.001)[0.007]$ & $1.001(-0.006)[0.005]$ \\
TS2 & $0.544(0.114)[0.312]$ & $0.545(-0.086)[0.541]$ & $0.565(-0.091)[0.526]$ & $0.602(-0.011)[0.409]$ \\
$\mathrm{C}_{2}$ & $0.116(0.051)[0.833]$ & $0.092(0.003)[0.905]$ & $0.000(0.083)[0.917]$ & $0.081(-0.002)[0.921]$ \\
${ }^{a}$ MPA values for $\mathrm{CH}_{3} \mathrm{Cl}$ are: $-0.188(\mathrm{Cl})$ and $-0.137(\mathrm{C}) .{ }^{b} \mathrm{MPA}$ values for $\mathrm{CH}_{3} \mathrm{Br}$ are: $-0.139(\mathrm{Br})$ and $-0.191(\mathrm{C})$.
\end{tabular}

relationship should only operate for the "inner" component of the rate constant and not for the global process. It was also inferred that the SIE values should correlate with the energy difference between the TS2 transition structure, and the $\mathrm{C}_{1}$ intermediate only when the $\mathrm{C}_{1} \rightarrow$ TS2 step is basically an electron transfer process. To confirm such conclusions in the present case, we have determined atomic charges and spin densities of the metal, halogen and $\mathrm{CH}_{3}$ moieties for the stationary points on the PESs in the framework of the Mulliken population analysis (MPA). Table 5 summarizes these data.

Table 5 shows that the positive charge on the alkaline-earth metal increases in value when we advance from $\mathrm{C}_{1}$ to $\mathrm{C}_{2}$ on the PESs. Similarly, the negative net charge on the halogen increases when passing from $\mathrm{C}_{1}$ to $\mathrm{C}_{2}$ through TS2. Regarding the spin density data it can be noted that in the intermediate $\mathrm{C}_{1}$, the metal moiety practically retains the unpaired electron of the isolated alkaline-earth metal. This metal spin density dramatically diminishes when moving from $\mathrm{C}_{1}$ to $\mathrm{C}_{2}$. In parallel, the spin density of the $\mathrm{CH}_{3}$ unit increases by the same amount. Consequently our results from the MPA suggest a SET "harpoon"-like mechanism that operates through an electron transfer from the metal, $\mathrm{M}$, to the $\mathrm{CH}_{3} \mathrm{X}$ unit in the transition state structure TS2.

The SIE values, for the alkaline-earth metals, computed at the mPW1k/QZVPP level are $349 \mathrm{kcal} \mathrm{mol}^{-1}\left(\mathrm{Mg}^{+}\right), 272 \mathrm{kcal}$
$\mathrm{mol}^{-1}\left(\mathrm{Ca}^{+}\right), 253 \mathrm{kcal} \mathrm{mol}^{-1}\left(\mathrm{Sr}^{+}\right)$and $227 \mathrm{kcal} \mathrm{mol}^{-1}\left(\mathrm{Ba}^{+}\right)$. On the other hand, the energy difference between the intermediate $\mathrm{C}_{1}$ and the transition state structure $\mathrm{TS} 2$ in the reactions between $\mathrm{M}^{+}(\mathrm{Mg}, \mathrm{Ca}, \mathrm{Sr}, \mathrm{Ba})$ and $\mathrm{CH}_{3} \mathrm{Cl} / \mathrm{CH}_{3} \mathrm{Br}$ are 33.43/ $31.26 \mathrm{kcal} \mathrm{mol}^{-1}\left(\mathrm{Mg}^{+}\right), 13.27 / 10.29 \mathrm{kcal} \mathrm{mol}^{-1}\left(\mathrm{Ca}^{+}\right), 12.9 /$ $9.56 \mathrm{kcal} \mathrm{mol}^{-1}\left(\mathrm{Sr}^{+}\right)$and 8.02/3.96 kcal mol${ }^{-1}\left(\mathrm{Ba}^{+}\right)$. (In these data the first value refers to the $\mathrm{CH}_{3} \mathrm{Cl}$ reactions whereas the second one corresponds to reactions with $\mathrm{CH}_{3} \mathrm{Br}$.) Thus, there is a clear correlation between SIE and $\mathrm{C}_{1} \rightarrow$ TS2 energy barriers, strongly suggesting that charge transfer will be the main force operating between the fragments $\mathrm{CH}_{3} \mathrm{X}$ and $\mathrm{M}^{+}$when reactants approach each other. On the other hand, no correlation between global rate constants and SIEs is found, because the "outer" transition state controls the global process.

In order to characterize the nature of the bonding in the stationary points of the PES we have performed a topological analysis of the electronic charge in the context of Bader's Quantum Theory of Atoms in Molecules (QTAIM). ${ }^{17}$ The main results of the QTAIM analysis for the $\mathrm{C}_{1}$, TS2, and C2 structures are collected in Tables 5 and 6. For comparative purposes, we have included in the tables the local topological properties of the electronic charge density distribution for the $\mathrm{CH}_{3} \mathrm{Cl}$ and $\mathrm{CH}_{3} \mathrm{Br}$ reactants. In addition, the corresponding contour maps of the Laplacian of electron density, including molecular graphs of electron density, are shown in Fig. 5. 
1 Table 6 Local topological properties (in a.u.) of the electronic charge density distribution calculated at the position of the bond critical points for different $\mathrm{CH}_{3} \mathrm{ClM}$ species ${ }^{a}$

\begin{tabular}{|c|c|c|c|c|c|c|}
\hline Species & & Bond & $\rho(r)$ & $\nabla^{2} \rho(r)$ & $|V(r)| / G(r)$ & $H(r)$ \\
\hline \multirow[t]{3}{*}{$\mathrm{CH}_{3} \mathrm{ClMg}$} & $\mathrm{C}_{1}$ & $\begin{array}{l}\mathrm{C}-\mathrm{Cl} \\
\mathrm{Cl}-\mathrm{Mg} \\
\mathrm{C}-\mathrm{H}\end{array}$ & $\begin{array}{l}0.170 \\
0.027 \\
0.299\end{array}$ & $\begin{array}{r}-0.231 \\
0.114 \\
-1.174\end{array}$ & $\begin{array}{r}2.868 \\
0.926 \\
10.299\end{array}$ & $\begin{array}{l}-0.124 \\
0.00196 \\
-0.329\end{array}$ \\
\hline & TS & $\begin{array}{l}\mathrm{C}-\mathrm{Cl} \\
\mathrm{Cl}-\mathrm{Mg} \\
\mathrm{C}-\mathrm{H}\end{array}$ & $\begin{array}{l}0.0502 \\
0.052 \\
0.304\end{array}$ & $\begin{array}{l}0.0703 \\
0.316 \\
-1.233\end{array}$ & $\begin{array}{r}1.318 \\
0.963 \\
11.291\end{array}$ & $\begin{array}{r}-0.008 \\
0.003 \\
-0.341\end{array}$ \\
\hline & $\mathrm{C}_{2}$ & $\begin{array}{l}\mathrm{C}-\mathrm{Mg} \\
\mathrm{Cl}-\mathrm{Mg} \\
\mathrm{C}-\mathrm{H}\end{array}$ & $\begin{array}{l}0.0269 \\
0.065 \\
0.291\end{array}$ & $\begin{array}{r}0.088 \\
0.379 \\
-1.118\end{array}$ & $\begin{array}{l}1.065 \\
1.014 \\
9.571\end{array}$ & $\begin{array}{l}-0.002 \\
-0.001 \\
-0.316\end{array}$ \\
\hline \multirow[t]{3}{*}{$\mathrm{CH}_{3} \mathrm{ClCa}$} & $\mathrm{C}_{1}$ & $\begin{array}{l}\mathrm{C}-\mathrm{Cl} \\
\mathrm{Cl}-\mathrm{Ca} \\
\mathrm{C}-\mathrm{H}\end{array}$ & $\begin{array}{l}0.172 \\
0.024 \\
0.294\end{array}$ & $\begin{array}{r}-0.239 \\
0.099 \\
-1.172\end{array}$ & $\begin{array}{r}2.902 \\
0.872 \\
10.166\end{array}$ & $\begin{array}{r}-0.127 \\
0.003 \\
-0.329\end{array}$ \\
\hline & $\mathrm{TS}$ & $\begin{array}{l}\mathrm{C}-\mathrm{Cl} \\
\mathrm{Cl}-\mathrm{Ca} \\
\mathrm{C}-\mathrm{H}\end{array}$ & $\begin{array}{l}0.064 \\
0.050 \\
0.300\end{array}$ & $\begin{array}{r}0.073 \\
0.183 \\
-1.181\end{array}$ & $\begin{array}{r}1.455 \\
1.071 \\
10.040\end{array}$ & $\begin{array}{l}-0.015 \\
-0.004 \\
-0.332\end{array}$ \\
\hline & $\mathrm{C}_{2}$ & $\begin{array}{l}\mathrm{C}-\mathrm{Ca} \\
\mathrm{Ca}-\mathrm{Cl} \\
\mathrm{C}-\mathrm{H}\end{array}$ & $\begin{array}{l}0.020 \\
0.071 \\
0.291\end{array}$ & $\begin{array}{r}0.062 \\
0.258 \\
-1.100\end{array}$ & $\begin{array}{l}0.984 \\
1.138 \\
8.953\end{array}$ & $\begin{array}{l}0.00025 \\
-0.010 \\
-0.315\end{array}$ \\
\hline \multirow[t]{3}{*}{$\mathrm{CH}_{3} \mathrm{ClSr}$} & $\mathrm{C}_{1}$ & $\begin{array}{l}\mathrm{C}-\mathrm{Cl} \\
\mathrm{Cl}-\mathrm{Sr} \\
\mathrm{C}-\mathrm{H}\end{array}$ & $\begin{array}{l}0.174 \\
0.021 \\
0.299\end{array}$ & $\begin{array}{r}-0.247 \\
0.081 \\
-1.163\end{array}$ & $\begin{array}{l}2.927 \\
0.851 \\
9.743\end{array}$ & $\begin{array}{l}-0.128 \\
0.0026 \\
-0.328\end{array}$ \\
\hline & $\mathrm{TS}$ & $\begin{array}{l}\mathrm{C}-\mathrm{Cl} \\
\mathrm{Cl}-\mathrm{Sr} \\
\mathrm{C}-\mathrm{H}\end{array}$ & $\begin{array}{l}0.0502 \\
0.044 \\
0.300\end{array}$ & $\begin{array}{c}0.0703 \\
0.147 \\
-1.178\end{array}$ & $\begin{array}{l}1.539 \\
1.068 \\
9.850\end{array}$ & $\begin{array}{l}-0.0189 \\
-0.003 \\
-0.332\end{array}$ \\
\hline & $\mathrm{C}_{2}$ & $\begin{array}{l}\mathrm{C}-\mathrm{Sr} \\
\mathrm{Cl}-\mathrm{Sr} \\
\mathrm{C}-\mathrm{H}\end{array}$ & $\begin{array}{l}0.018 \\
0.066 \\
0.293\end{array}$ & $\begin{array}{r}0.053 \\
0.199 \\
-1.114\end{array}$ & $\begin{array}{l}0.954 \\
1.177 \\
8.814\end{array}$ & $\begin{array}{c}0.0006 \\
-0.011 \\
-0.319\end{array}$ \\
\hline \multirow[t]{3}{*}{$\mathrm{CH}_{3} \mathrm{ClBa}$} & $\mathrm{C}_{1}$ & $\begin{array}{l}\mathrm{C}-\mathrm{Cl} \\
\mathrm{Cl}-\mathrm{Ba} \\
\mathrm{C}-\mathrm{H}\end{array}$ & $\begin{array}{l}0.175 \\
0.022 \\
0.299\end{array}$ & $\begin{array}{r}-0.251 \\
0.081 \\
-1.162\end{array}$ & $\begin{array}{l}2.944 \\
0.859 \\
9.702\end{array}$ & $\begin{array}{c}-0.129 \\
0.0023 \\
-0.328\end{array}$ \\
\hline & $\mathrm{TS}$ & $\begin{array}{l}\mathrm{C}-\mathrm{Cl} \\
\mathrm{Cl}-\mathrm{Ba} \\
\mathrm{C}-\mathrm{H}\end{array}$ & $\begin{array}{l}0.098 \\
0.046 \\
0.298\end{array}$ & $\begin{array}{r}0.023 \\
0.150 \\
-1.150\end{array}$ & $\begin{array}{l}1.866 \\
1.074 \\
9.233\end{array}$ & $\begin{array}{l}-0.037 \\
-0.003 \\
-0.327\end{array}$ \\
\hline & $\mathrm{C}_{2}$ & $\begin{array}{l}\mathrm{C}-\mathrm{Ba} \\
\mathrm{Cl}-\mathrm{Ba} \\
\mathrm{C}-\mathrm{H}\end{array}$ & $\begin{array}{l}0.017 \\
0.067 \\
0.293\end{array}$ & $\begin{array}{r}0.047 \\
0.169 \\
-1.112\end{array}$ & $\begin{array}{l}0.945 \\
1.238 \\
8.866\end{array}$ & $\begin{array}{l}0.0006 \\
-0.012 \\
-0.320\end{array}$ \\
\hline $\mathrm{CH}_{3} \mathrm{Cl}$ & & $\begin{array}{l}\mathrm{C}-\mathrm{Cl} \\
\mathrm{C}-\mathrm{H}\end{array}$ & $\begin{array}{l}0.192 \\
0.296\end{array}$ & $\begin{array}{l}-0.304 \\
-1.127\end{array}$ & $\begin{array}{l}3.134 \\
8.913\end{array}$ & $\begin{array}{l}-0.143 \\
-0.323\end{array}$ \\
\hline
\end{tabular}

${ }^{a}$ The electronic charge density $[\rho(r)]$, the Laplacian $\left[\nabla^{2} \rho(r)\right]$, the relationship between the potential energy density $V(r)$ and the Lagrangian form of kinetic energy density $G(r)$, and the total energy density, $[H(r)]$.

Within the QTAIM formalism, critical points on the oneelectron density are identified. In the $\mathrm{C}_{1}$, TS2 and $\mathrm{C}_{2}$ structures only $(3,-1)$ bond critical points (BCP) were found. These correspond to a minimum value of $\rho(r)$ along the line connecting the nuclei and a maximum along the interatomic surfaces.

For each $\mathrm{C}_{1}$, TS2 and $\mathrm{C}_{2}$ structures we have characterized five BCPs, namely one BCP between the alkaline-earth atom and the halogen atom, three BCPs between the carbon atom and the hydrogen atoms, and one BCP corresponding to the bond between
Table 7 Local topological properties (in a.u.) of the electronic charge density distribution calculated at the position of the bond critical points for different $\mathrm{CH}_{3} \mathrm{BrM}$ species ${ }^{a}$

\begin{tabular}{|c|c|c|c|c|c|c|}
\hline Species & & Bond & $\rho(r)$ & $\nabla^{2} \rho(r)$ & $|V(r)| / \mathrm{G}(r)$ & $H(r)$ \\
\hline \multirow{9}{*}{$\overline{\mathrm{CH}_{3} \mathrm{BrMg}}$} & \multirow[t]{3}{*}{$\mathrm{C}_{1}$} & $\mathrm{C}-\mathrm{Br}$ & 0.146 & -0.159 & 2.836 & -0.087 \\
\hline & & $\mathrm{Br}-\mathrm{Mg}$ & 0.026 & 0.085 & 1.011 & -0.0002 \\
\hline & & C-Hplano & 0.299 & -1.166 & 10.013 & -0.328 \\
\hline & \multirow[t]{3}{*}{ TS } & $\mathrm{C}-\mathrm{Br}$ & 0.049 & 0.055 & 1.355 & -0.008 \\
\hline & & $\mathrm{Br}-\mathrm{Mg}$ & 0.045 & 0.231 & 0.984 & 0.0009 \\
\hline & & C-Hplano & 0.304 & -1.220 & 10.809 & -0.340 \\
\hline & \multirow[t]{3}{*}{$\mathrm{C}_{2}$} & $\mathrm{C}-\mathrm{Mg}$ & 0.027 & 0.086 & 1.067 & 0.0015 \\
\hline & & $\mathrm{Mg}-\mathrm{Br}$ & 0.057 & 0.275 & 1.036 & -0.003 \\
\hline & & $\mathrm{C}-\mathrm{H}$ & 0.292 & -1.120 & 9.536 & -0.317 \\
\hline \multirow[t]{9}{*}{$\mathrm{CH}_{3} \mathrm{BrCa}$} & \multirow[t]{3}{*}{$\mathrm{C}_{1}$} & $\mathrm{Br}-\mathrm{C}$ & 0.147 & -0.162 & 2.850 & -0.088 \\
\hline & & $\mathrm{Br}-\mathrm{Ca}$ & 0.024 & 0.0784 & 0.936 & 0.001 \\
\hline & & C-Hplano & 0.299 & -1.164 & 9.900 & -0.328 \\
\hline & \multirow[t]{3}{*}{ TS } & $\mathrm{C}-\mathrm{Br}$ & 0.065 & 0.052 & 1.544 & -0.016 \\
\hline & & $\mathrm{Br}-\mathrm{Ca}$ & 0.045 & 0.147 & 1.085 & -0.003 \\
\hline & & C-Hplano & 0.299 & -1.171 & 9.809 & -0.330 \\
\hline & \multirow[t]{3}{*}{$\mathrm{C}_{2}$} & $\mathrm{Br}-\mathrm{Ca}$ & 0.062 & 0.194 & 1.151 & -0.009 \\
\hline & & $\mathrm{C}-\mathrm{Ca}$ & 0.020 & 0.062 & 0.984 & 0.0002 \\
\hline & & C-Hplano & 0.291 & -1.101 & 8.930 & -0.315 \\
\hline \multirow[t]{9}{*}{$\mathrm{CH}_{3} \mathrm{BrSr}$} & \multirow[t]{3}{*}{$\mathrm{C}_{1}$} & $\mathrm{C}-\mathrm{Br}$ & 0.148 & -0.166 & 2.863 & -0.090 \\
\hline & & $\mathrm{Br}-\mathrm{Sr}$ & 0.020 & 0.062 & 0.904 & 0.0014 \\
\hline & & $\mathrm{C}-\mathrm{H}$ & 0.299 & -1.157 & 9.561 & -0.327 \\
\hline & \multirow[t]{3}{*}{ TS } & $\mathrm{C}-\mathrm{Br}$ & 0.067 & 0.054 & 1.548 & -0.0165 \\
\hline & & $\mathrm{Br}-\mathrm{Sr}$ & 0.040 & 0.109 & 1.103 & -0.003 \\
\hline & & $\mathrm{C}-\mathrm{H}$ & 0.299 & -1.162 & 9.527 & -0.329 \\
\hline & \multirow[t]{3}{*}{$\mathrm{C}_{2}$} & $\mathrm{C}-\mathrm{Sr}$ & 0.018 & 0.053 & 0.956 & 0.0006 \\
\hline & & $\mathrm{Br}-\mathrm{Sr}$ & 0.056 & 0.149 & 1.179 & -0.008 \\
\hline & & $\mathrm{C}-\mathrm{H}$ & 0.293 & -1.114 & 8.814 & -0.319 \\
\hline \multirow[t]{9}{*}{$\mathrm{CH}_{3} \mathrm{BrBa}$} & \multirow[t]{3}{*}{$\mathrm{C}_{1}$} & $\mathrm{C}-\mathrm{Br}$ & 0.149 & -0.167 & 2.869 & -0.090 \\
\hline & & $\mathrm{Br}-\mathrm{Ba}$ & 0.021 & 0.063 & 0.920 & 0.0011 \\
\hline & & $\mathrm{C}-\mathrm{H}$ & 0.299 & -1.156 & 9.524 & -0.327 \\
\hline & \multirow[t]{3}{*}{ TS } & $\mathrm{C}-\mathrm{Br}$ & 0.093 & 0.015 & 1.897 & -0.033 \\
\hline & & $\mathrm{Br}-\mathrm{Ba}$ & 0.040 & 0.117 & 1.087 & -0.003 \\
\hline & & $\mathrm{C}-\mathrm{H}$ & 0.296 & -1.135 & 8.922 & -0.325 \\
\hline & \multirow[t]{3}{*}{$\mathrm{C}_{2}$} & $\mathrm{C}-\mathrm{Ba}$ & 0.017 & 0.048 & 0.947 & 0.0005 \\
\hline & & $\mathrm{Br}-\mathrm{Ba}$ & 0.057 & 0.132 & 1.221 & -0.008 \\
\hline & & $\mathrm{C}-\mathrm{H}$ & 0.293 & -1.111 & 8.870 & -0.319 \\
\hline \multirow[t]{2}{*}{$\mathrm{CH}_{3} \mathrm{Br}$} & & $\mathrm{C}-\mathrm{Br}$ & 0.158 & -0.192 & 2.932 & -0.0992 \\
\hline & & $\mathrm{C}-\mathrm{H}$ & 0.296 & -1.125 & 8.812 & -0.322 \\
\hline
\end{tabular}

${ }^{a}$ The electronic charge density $[\rho(r)]$, the Laplacian $\left[\nabla^{2} \rho(r)\right]$, the relationship between the potential energy density $V(r)$ and the Lagrangian form of kinetic energy density $G(r)$, and the total energy density, $[H(r)]$.

the carbon atom and the halogen atom, in the $\mathrm{C}_{1}$ and TS2 structures. In $\mathrm{C}_{2}$ structures the last $\mathrm{BCP}$ corresponds to the bond between the carbon atom and the alkaline-earth atom. It should be stressed that in the transition structures of the reactions of the magnesium monocation, no BCP was found between carbon and metal atoms, and consequently no ring critical point appears, even though, $a$ priori, the TS2 structure resembles a three-membered ring.

The local topological properties of the carbon-hydrogen BCPs are indicative of shared interactions: large values of
1 5 
Fig. 6 Contour maps of the Laplacian distribution of electron density for different critical points. Red dashed lines indicate regions of electronic charge concentration $\left(\nabla^{2} \rho(r)<0\right)$, and blue continuous lines denote regions of electronic charge depletion $\left(\nabla^{2} \rho(r)>0\right)$. Also molecular graphs of electron density are shown; small red spheres represent bond critical points (BCPs).

electron density, negative values of its Laplacian, $|V(r)| / G(r) \mid$ ratios greater than 2 and negative values of the total energy densities $\mathrm{H}(r)$. It should be noted that there are two different types of $\mathrm{C}-\mathrm{H}$ BCPs, one of them corresponds to the interactions between carbon and nonplanar hydrogens, and the other one is related to the carbon-planar hydrogen interaction. However, both $\mathrm{C}-\mathrm{H}$ interactions show almost identical values of the local topological properties of the electronic charge density distribution and in Tables 6 and 7 we have not made any distinction between the different hydrogen atoms.

Regarding the overall halogen-metal BCPs, it can be inferred that the properties of the electron densities are compatible with closed-shell interactions: all have low values of electron density, positive values of its Laplacian $\left(\nabla^{2} \rho(r)>0\right)$, the $|V(r)| / G(r) \mid$ ratios are close to 1 , and the total energy density $H(r)$ is negative with small values.

As we advance in the reaction from $\mathrm{C}_{1}$ to TS2, the halogenmetal distance shortens and the value of electron density and its Laplacian increases, suggesting a greater degree of covalence in the TS2 structure than in the encounter complex $\mathrm{C}_{1}$.

In the $\mathrm{C}_{1}$ structures, the carbon-halogen BCPs show moderate values of the electronic charge density, $\rho(r)$, and negative values of the Laplacian, $\nabla^{2} \rho(r)$. Moreover, the $|V(r)| / G(r)$ ratios are greater than 2 and the total energy densities $H(r)$ have negative values. Consequently, the carbon-halogen interactions can be classified as polar covalent interactions. It is interesting to note that in the transition state structures the C-X BCPs present low values of $\rho(r)$ and positive values of its Laplacian in consonance with closed-shell interactions. However, the $|V(r)| / G(r) \mid$ ratios and $\mathrm{H}(r)$ values are indicative of a certain degree of covalence in this bond. These features can be visualized in Fig. 5. In the $\mathrm{C}_{1}$ intermediates, the carbonhalogen BCPs lie in a zone of concentration of charge that corresponds to the region where $\nabla^{2} \rho(r)<0$, thus indicating the presence of a shared interaction. In contrast, the C-X BCPs in TS2 are located in regions of depletion of electronic charge density $\left(\nabla^{2} \rho(r)>0\right)$ or closed-shell interactions (Fig. 6).

On the other hand, it can also be observed that as advancing from magnesium to barium in the group of the periodic table, the degree of covalence slightly increases in the $\mathrm{C}-\mathrm{X}$ interactions. By comparing the carbon-halogen local topological properties of the electronic charge density distribution corresponding to $\mathrm{C}_{1}$ structures and the isolated $\mathrm{CH}_{3} \mathrm{X}$, we find a lesser degree of covalence in the $\mathrm{C}_{1}$ intermediates than in the $\mathrm{CH}_{3} \mathrm{X}$ reactants.

In the $\mathrm{C}_{2}$ structures the carbon-metal BCPs show low values of $\rho(r)$ and slightly positive values of its Laplacian. The $|V(r)| /$ $G(r) \mid$ ratios are between 1 and 2 and $H(r)$ is negative with a low 
value. Thus these interactions can be classified as closed shell interactions with a small degree of covalence.

\section{Conclusions}

In this paper, we have carried out a computational thermodynamic and kinetics study of the reactions between alkalineearth metal monocations $\left(\mathrm{Mg}^{+}, \mathrm{Ca}^{+}, \mathrm{Sr}^{+}\right.$and $\left.\mathrm{Ba}^{+}\right)$and halogen

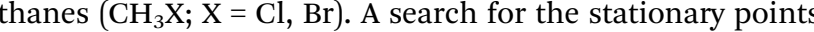
involved in these reactions has been performed, at the Density Functional Theory (DFT) level, using the $\mathrm{mPW} \mathrm{K}^{19}$ functional in conjunction with the QZVPP Ahlrichs's basis sets. ${ }^{21}$ In addition, kinetics calculations have been accomplished in the sition state theory. ${ }^{13}$

The reactions of $\mathrm{Mg}^{+}$with either $\mathrm{CH}_{3} \mathrm{Cl}$ or $\mathrm{CH}_{3} \mathrm{Br}$ are clearly endothermic $\left(\Delta U_{0}=8.13 / 5.80 \mathrm{kcal} \mathrm{mol}^{-1}\right)$ and have significant energetic barriers $\left(\Delta U_{0}=11.77 / 9.53 \mathrm{kcal} \mathrm{mol}^{-1}\right)$. Thus for these reactions, under adequate experimental conditions, the formation of a $\left[\mathrm{CH}_{3} \mathrm{XMg}\right]^{+}$adduct complex should be expected.

The reactions involving $\mathrm{Ca}^{+}, \mathrm{Sr}^{+}$and $\mathrm{Ba}^{+}$are exothermic and barrierless processes. The most exothermic reactions are those initiated by the barium monocation $\left(\Delta U_{0}=-34.68 /-34.43 \mathrm{kcal}\right.$ $\mathrm{mol}^{-1}$ ).

Taking together the two halomethanes considered in our study, it can be concluded that no qualitative significant differences were observed in the energetics of the stationary points on the PESs when bromine substitutes chlorine in the halomethane molecule.

According to our kinetics results, in the reactions of the magnesium monocation, the rate constant is controlled by the "inner" bottleneck as a direct consequence of the existence of important activation barriers in these reactions. The rate coefficients, at $295 \mathrm{~K}$, for the reactions of $\mathrm{Mg}^{+}$with $\mathrm{CH}_{3} \mathrm{Cl} / \mathrm{CH}_{3} \mathrm{~B}$ are $k_{\text {global }}=4.89 \times 10^{-20} / 4.89 \times 10^{-18} \mathrm{~cm}^{3}$ molecule ${ }^{-1} \mathrm{~s}^{-1}$.

The global rate constant for the reactions of $\mathrm{Ca}^{+}+\mathrm{CH}_{3} \mathrm{Cl}$ / $\mathrm{CH}_{3} \mathrm{Br}$ is mainly controlled by the "outer" component, especially at low temperatures. As the temperature increases both tions to the global process. At 295, our computed rate coefficients for these reactions are, respectively, $k_{\text {global }}=1.72 \times 10^{-9} /$ $2.74 \times 10^{-9} \mathrm{~cm}^{3}$ molecule $\mathrm{s}^{-1}$.

The kinetics of the reactions between $\mathrm{Sr}^{+} / \mathrm{Ba}^{+}$and $\mathrm{CH}_{3} \mathrm{Cl} /$ $\mathrm{CH}_{3} \mathrm{Br}$ is controlled by the "outer" bottleneck in the whole range of temperatures considered in our study. In the reactions of $\mathrm{Sr}^{+}$and $\mathrm{CH}_{3} \mathrm{Cl} / \mathrm{CH}_{3} \mathrm{Br}$, the rate coefficients evaluated at $295 \mathrm{~K}$ are $k_{\text {global }}=1.13 \times 10^{-9} / 1.1410^{-9} \mathrm{~cm}^{3}$ molecule $\mathrm{s}^{-1}$. Whereas, for the reactions of $\mathrm{Ba}^{+}$and $\mathrm{CH}_{3} \mathrm{Cl} / \mathrm{CH}_{3} \mathrm{Br}$, the rate constants at $295 \mathrm{~K}$ are $k_{\text {global }}=1.54 \times 10^{-9} / 8.87 \times 10^{-10} \mathrm{~cm}^{3}$ molecule ${ }^{-1} \mathrm{~s}^{-1}$. According to our previous experience, ${ }^{13-16}$ the above kinetics predictions should represent a reasonable approach to the corresponding experimental measurements, not yet available.

The Mulliken population analysis for the stationary points on the PESs supports a mechanistic picture in which an electron transfer from the alkaline-earth metal monocation to the $\mathrm{CH}_{3} \mathrm{X}$ moiety in the TS2 transition structure takes place. Thus according to our results the reactions studied in this paper seem to proceed through a "harpoon"-like mechanism for the halogen-atom abstraction.

An analysis of the bonding situation for the stationary points on the PESs for these reactions has been performed in the framework of the QTAIM formalism. It is shown that when advancing in the reaction from $\mathrm{C}_{1}$ to TS2 the halogen-metal bond, which has a closed-shell character in the $\mathrm{C}_{1}$ structures, acquires a certain degree of covalency in the transition state structure TS2. Meanwhile, the carbon-halogen interaction, which shows a covalent character in the $\mathrm{C}_{1}$ structures, acquires an important degree of closed-shell character in the TS2 structures.

Finally, our thermodynamic and kinetics studies show that carbon-halogen bonds in halomethanes can easily be activated by calcium, strontium and barium monocations forming the metal halogen cation.

\section{Acknowledgements}

Financial support from the Spanish "Ministerio de Educación y Ciencia" (Grant QCT2010-16864) and the "Junta de Castilla y León” (GrantVA077U13) is gratefully acknowledged.

\section{References}

1 Z. Zhao, G. K. Koyanagi and B. K. Bohme, J. Phys. Chem. A, 2006, 110, 10607.

2 D. Caraiman and D. K. Bohme, J. Phys. Chem. A, 2002, 106, 9705.

3 V. V. Lavrov, V. Blagojevic, G. K. Koyanagi, G. Orlova and D. K. Bohme, J. Phys. Chem. A, 2004, 108, 5610.

4 G. K. Koyanagi, V. I. Baranov, S. D. Tanner and D. K. Bohme, J. Anal. At. Spectrom., 2000, 15, 1207.

5 G. K. Koyanagi, V. Lavrov, V. I. Baranov, D. Bandura, S. D. Tanner, J. W. McLaren and D. K. Bohme, Int. J. Mass Spectrom., 2000, 194, L1.

6 E. R. Fischer, J. L. Elkind, D. E. Clemmer, R. Georgiadis, S. K. Loh, N. Aristov, L. S. Sunderlin and P. B. Armentrout, J. Chem. Phys., 1990, 93, 2676.

7 M. M. Kappes and R. H. Staley, J. Phys. Chem., 1981, 85, 942. 8 J. S. Muenter and V. W. Laurie, J. Chem. Phys., 1966, 45, 855. 9 R. G. Shulman, B. P. Dailey and C. H. Townes, Phys. Rev., 1950, 78, 145.

10 C. Heinemann, N. Goldberg, I. C. Tornieporth-Oething, T. M. Klapötke and H. Schwarz, Angew. Chem., Int. Ed. Engl., 1995, 34, 213.

11 D. Zhang, C. Liu and S. Bi, J. Phys. Chem. A, 2002, 106, 4153. 12 J. N. Harvey, D. Schröder, W. Koch, D. Danovich, S. Shaik and H. Schwarz, Chem. Phys. Lett., 1997, 278, 391.

13 A. Varela-Álvarez, V. M. Rayón, P. Redondo, C. Barrientos and J. A. Sordo, J. Chem. Phys., 2009, 131, 124309. 
114 A. Varela-Álvarez, J. A. Sordo, P. Redondo, A. Largo, C. Barrientos and V. M. Rayón, Theor. Chem. Acc., 2011, 128, 609.

15 P. Redondo, A. Varela-Álvarez, V. M. Rayón, A. Largo, J. A. Sordo and C. Barrientos, J. Phys. Chem. A, 2013, 117, 2932.

16 C. Barrientos, V. M. Rayón, A. Largo, J. A. Sordo and P. Redondo, J. Phys. Chem. A, 2013, 117, 7742.

17 R.-W. F Bader, Atoms in Molecules: A Quantum Theory, Clarendon Press, New York, 1990.

18 B. J. Lynch, P. L. Fast, M. Harris and D. G. Truhlar, J. Phys. Chem. A, 2000, 104, 4811.

19 Y. Zhao, J. Pu, B. J. Lynch and D. G. Truhlar, Phys. Chem. Chem. Phys., 2004, 6, 673.

20 C. Adamo and V. Barone, J. Chem. Phys., 1998, 208, 664.

21 F. Weigend and R. Ahlrichs, Phys. Chem. Chem. Phys., 2005, 7, 3297.

22 C. Gonzólez and H. B. Schlegel, J. Phys. Chem., 1990, 94, 5523.

23 M. J. Frisch, G. W. Trucks, H. B. Schlegel, G. E. Scuseria, M. A. Robb, J. R. Cheeseman, G. Scalmani, V. Barone, B. Mennucci and G. A. Petersson, Gaussian 09, Gaussian, Inc., Wallingford, CT, 2009.

24 R. W. F. Bader, Chem. Rev., 1991, 91, 893.

25 W. H. E. Schwarz, P. Valtazanos and K. Ruedenberg, Theor. Chim. Acta, 1985, 68, 471.

26 C. Gatti, Phys. Scr., 2013, 87, 048102.
27 D. Cremer and E. Kraka, Angew. Chem., Int. Ed. Engl., 1984, 23, 627.

28 T. A. Keith, AIMAll, version 13.11.04, Professional, TK Gristmill Software: Overland Park, KS, 2013, http://aim.tkgrist mill.com.

29 M. Mozurkewich and S. W. Benson, J. Phys. Chem., 1984, 88, 6429.

30 W. Forst, Theory of Unimolecular Reactions, Academic Press, New York, 1973.

31 R. G. Gilbert and S. C. Smith, Theory of Unimolecular and Recombination Reactions, Blackwell Sci. Pu., Oxford, 1990.

32 T. Baer and W. L. Hase, Unimolecular Reaction Dynamics: Theory and Experiments, Oxford University Press, New York, 1996.

33 Y. Chen, A. Rauk and E. Tschkuikow-Roux, J. Phys. Chem., 1991, 95, 9900.

34 B. C. Garrett and D. G. Truhlar, J. Chem. Phys., 1979, 70, 1593.

35 X. Hu and W. L. Hase, J. Chem. Phys., 1991, 95, 8073.

36 J. Villá and D. G. Truhlar, Theor. Chem. Acc., 1997, 97, 317.

37 J. Villá, A. González-Lafont, J. M. Lluch, J. C. Corchado and J. García-Espinosa, J. Chem. Phys., 1997, 107, 7266.

38 C. Heinemann, N. Goldberg, I. C. Tornieporth-Oething, T. M. Klapötke and H. Schwarz, Angew. Chem., Int. Ed. Engl., 1995, 34, 213.

39 D. Zhang, C. Liu and S. Bi, J. Phys. Chem. A, 2002, 106, 4153. 